Invited article

\title{
The use and misuse of magnetic methods to monitor environmental pollution in urban areas
}

\author{
Uso y abuso de métodos magnéticos en el monitoreo de contaminación ambiental en áreas \\ urbanas
}
Kathrin Lisa Kapper ${ }^{1, *}$, Francisco Bautista ${ }^{2}$, Avto Goguitchaishvili ${ }^{1}$, María Felicidad Bógalo ${ }^{3}$, Rubén Gejudo-Ruíz ${ }^{1}$, Miguel Cervantes Solano ${ }^{4}$

\begin{abstract}
${ }^{1}$ Laboratorio Universitario de Geofísica Ambiental, Instituto de Geofisica, Unidad Michoacán, Universidad Nacional Autónoma de México, Campus Morelia, 58190 Morelia, Mexico.

${ }^{2}$ Laboratorio Universitario de Geofísica Ambiental, Centro de Investigaciones en Geografía Ambiental, Universidad Nacional Autónoma de México, Campus Morelia, 58089 Morelia, Mexico.
\end{abstract}

${ }^{3}$ Departamento de Física, Escuela Politécnica Superior, Universidad de Burgos, Avda. Cantabria s/n, 09006, Burgos, Spain.

${ }^{4}$ Laboratorio Interinstitucional de Magnétismo Natural, Escuela Nacional de Estudios Superiores Campus Morelia, Universidad Nacional Autónoma de México, Campus Morelia, 58190 Morelia, Mexico.

* Corresponding author: (K. L. Kapper)

lisa.kapper@igeofisica.unam.mx

\section{Gitation:}

Kapper, K.L., Bautista, F., Goguitchaishvili, A., Bógalo, M.F., Cejudo-Ruíz, R., Cervantes Solano, M., 2020, The use and misuse of magnetic methods to monitor environmental pollution in urban areas: Boletín de la Sociedad Geológica Mexicana, 72(1), A111219. http:// dx.doi.org/10.18268/BSGM2020v72nla1 11219

Manuscript received: August 27, 2018. Corrected manuscript received: April 16, 2019. Manuscript accepted: May 25, 2019

Peer Review under the responsability of Universidad Nacional Autónoma de México.

This is an open access article under the lisence $C C B Y-N C-S A$ (https://creativecommons.org/licenses/by-nc-sa/4.0/)

\section{ABSTRACT}

This review compiles the current understanding of magnetic monitoring of natural and anthropogenic pollutants, with the focus on biological matrices. Magnetic methods are used to identify ferromagnetic (s.l.) minerals, which serve as tracer for anthropogenic pollutants. These methods have become more popular in the last two decades due to their cost-effectiveness and rapid implementation compared to chemical analyses. The growing interest in the study of anthropogenic pollution arose due to advancements in the understanding of the negative effects of pollutants to our health and the ecosystem. The importance of quantifying the amount, type, and pathways of pollutants is obvious in air quality regulation policies and strategies to mitigate pollution in urban areas. In this context, this article reviews the pathways and matrices of pollutants, magnetic mineral proxies, and their measurements and interpretation. Furthermore, the most recent results within the area of magnetic monitoring in urban areas are presented, including their advantages as well as shortcomings. The review concludes with potential future steps of magnetic studies applied to anthropogenic pollution and their conclusions.

Keywords: Biomagnetic monitoring, Environmental pollution, Anthropogenic pollutants, Particulate matter, Heavy metals, Health.

\section{RESUMEN}

Esta revisión compila la comprensión actual de la monitorización magnética de contaminantes naturales y antropogénicos, con el enfoque en matrices biológicas. Los métodos magnéticos se utilizan para identificar minerales ferromagnéticos (s.l.), que sirven como trazadores de contaminantes antropogénicos. Estos métodos se han vuelto más populares en las últimas dos décadas debido a su rentabilidad y rápida implementación, en comparación con los análisis químicos. El creciente interés en el estudio de la contaminación antropogénica surgió debido a los avances en la comprensión de los efectos negativos de los contaminantes para nuestra salud y el ecosistema. La importancia de cuantificar la cantidad, el tipo y las vías de los contaminantes es evidente en las politicas de regulación de la calidad del aire y en las estrategias para mitigar la contaminación en zonas urbanas. En este contexto, este artículo revisa las rutas y matrices de contaminantes, proxies de minerales magnéticos y sus mediciones e interpretaciones. Además, se presentan los resultados más recientes dentro del área de monitoreo magnético en áreas urbanas, que incluyen sus ventajas y deficiencias. La revisión concluye con posibles pasos futuros de estudios magnéticos aplicados a la contaminación antropogénica y sus conclusiones.

Palabras clave: Monitoreo biomagnético, Contaminación ambiental, Contaminantes antropogénicos, Partículas, Metales pesados, Salud. 


\section{Introduction}

Man-made pollution of the atmosphere, hydrosphere, pedosphere, and biosphere has grown in recent years. According to the World Health Organization (WHO), 92\% of the world's present population lives in places where air quality is worse than the limits set by the WHO (2016). Therefore, monitoring pollution levels especially in urban areas, where more than half of the world's population lives, is of utmost importance. Anthropogenic particulate matter (PM) accounts for about $10 \%$ of the total global aerosol amount, but with large regional differences (Perrino et al., 2010). The dangers posed by pollutants to health, the environmental system, and the atmospheric radiation budget have been shown in numerous studies (e.g., Pope III et al., 1992; Luo et al., 2012; Maher et al., 2016; Salmani-Ghabeshi et al., 2016; Song et al., 2016; Bourliva et al., 2017; Cao, 2017). Current investigations focus on the identification of highly polluted areas through direct monitoring, (bio)magnetic monitoring, backward modeling of sources and pathways of pollutant agents, and forecasts of high-pollution events.

Direct geochemical monitoring is often time-consuming, laborious, and costly, whereas magnetic methods are fast and inexpensive (Petrovský and Ellwood, 1999). Magnetic methods identify the amount, concentration, type, and grain sizes of iron oxides, iron hydroxides, and sulphides that are linked to heavy metals. Furthermore, magnetic techniques have shown to be capable of discriminating between different sources of pollution (e.g., Hoffmann et al., 1999, Hansard et al., 2012; Zhang et al., 2012;). Specifically, biomagnetic monitoring uses magnetic methods to identify ferromagnetic (s.l.) PM captured by biological matrices.

Already in 1926, Gustav Ising studied environmental processes in a glacial setting using magnetic minerals (Maher, 2007). In his pioneering work he measured magnetic susceptibility and natural magnetic remanence of annually laminated lake sediments from Sweden. He found that the magnetic properties of the sediments varied seasonally and with distance from their ice margin source (Maher, 2007). Thompson formally defined environmental magnetism as a discipline in the 1980s (Thompson et al., 1980). The materials investigated in environmental studies include soils, sediments, dust, rocks, organic tissues, and manmade materials. The magnetic properties of the different materials are used as proxies, for example, for provenance analysis of sedimentary basins, pollution assessment, and paleoclimate studies (Dekkers, 1997). The matrices used to investigate pollution in urban areas are predominantly soils and sediments, which act as long-term archives of pollution; urban dust taken from streets; plants and other surfaces; and airborne particles from air filters.

The close relationship between ferromagnetic (s.l.) minerals and heavy metals and other pollutants has been shown by combined analyses of chemical and magnetic data (Hanesch et al., 2007; Aguilar Reyes et al., 2012; 2013; Cejudo-Ruíz et al., 2015). Hazardous particles can be traced with magnetic minerals, because the latter are able to incorporate heavy metals in their structure (Scoullos et al., 1979; Oldfield and Scoullos, 1984; Thompson and Oldfield, 1986; Flanders, 1994; Matzka and Maher, 1999). For example, industrially derived magnetic minerals share an origin and existence with heavy metals and thus can be used as tracers of pollution (e.g., Scholger, 1998; Evans and Heller, 2003). Heavy metals can be absorbed, adsorbed, or incorporated in the structure of magnetic minerals. For example, $\mathrm{Mn}, \mathrm{Ni}$, and $\mathrm{Co}$ can be incorporated directly into the structure of goethite (Cornell, 1991). Georgeaud et al. (1997) reported that magnetite is a possible carrier of heavy metals such as $\mathrm{Pb}, \mathrm{Cd}, \mathrm{Cr}$, or Ni. Particles finer in size than $10 \mu \mathrm{m}$ - called $\mathrm{PM}_{10}$ - have a high specific surface, which makes these particles efficient carriers of pollutants such as heavy metals and polycyclic aromatic hydrocarbons (PAH) (Hoffmann et al., 1999; Lu et al., 2011). Laboratory studies of iron oxides in redbeds revealed that these particles are highly adsorbent of heavy metals (Rose and Bianchi-Mosquera, 1993). 
Most commonly, measurements of magnetic susceptibility and isothermal remanent magnetization are used as proxy methods for the accumulation of heavy metals. However, heavy metals are not equally well correlated with these magnetic parameters. Soils, sediments and dusts contain a complex natural mixture of magnetic minerals of different grain sizes (Hoffmann et al., 1999). Therefore, it is necessary separating the anthropogenic magnetic signal from its natural background (Hoffmann et al., 1999; Yang et al., 2015). However, the approaches used so far are diverse and approximate, which makes a comparison between different studies difficult.

The aim of this review focuses on biomagnetic monitoring of ferromagnetic (s.l.) minerals used as tracers for pollutants, including its advances and current weaknesses. First, the pollutants found in the pedo-, hydro-, bio-, and atmosphere are presented, including their harm to humans and the ecosystem. This is followed by an introduction of the ferromagnetic tracer minerals, their detection and the implications of the magnetic parameters. Subsequently, a thorough review of current advances of biomagnetic monitoring of anthropogenic pollution in urban centers is presented, followed by an outlook on future environmental studies. Finally, conclusions are drawn about the current state of research.

\section{Pollutants, their pathways and matrices}

Primary pollutants, such as heavy metals that derive from natural or anthropogenic sources, are discharged directly into the troposphere (Smith, 1990). Dust containing heavy metals is dispersed globally by atmospheric circulation and becomes a significant component of sediments, soils, biosphere, and hydrosphere. The most common heavy metals of anthropogenic origin have a variety of sources, including vehicular and industrial combustion, heating, and abrasion processes. In recent years, man-made iron oxides from combustion of fossil fuel, particles caused by the wear of roads and tires, metal smelting, production of cement, coal burning power plants or steel manufacture, and agricultural processes have made their way into the environmental system (Thompson and Oldfield, 1986; Evans and Heller, 2003). Elements such as $\mathrm{Pb}$ originate from leaded gasoline, whereas $\mathrm{Cu}, \mathrm{Zn}$, and $\mathrm{Cd}$ derive from car components, abrasion of tires, lubricants, and industrial or incinerator emissions. The corrosion of cars and the chrome plating of vehicle parts free particles $\mathrm{Ni}$ and $\mathrm{Cr}$; and As stems from emissions of fossil fuel combustion, from industrial activities, and from the use of pesticides and pigments (Zhang et al., 2012).

Iron oxides are among the most omnipresent components of natural materials, accounting for about 2\% of Earth's crust. They form part of natural processes in the lithosphere that involve large-scale and long-term material movement, mountain building, sea-floor spreading, and rock weathering. Further sources of iron oxides are the eruption and flow of lavas, dispersal of volcanic ashes, and transport of eroded sediments (Figure 1; e.g., Thompson and Oldfield, 1986). A small and generally insignificant amount of iron oxides arrives as cosmic flux.

These natural and anthropogenic magnetic minerals reach the atmosphere as fly ash. They remain there for weeks or months and can be transported for hundreds to thousands of kilometers (Evans and Heller, 2003; Johansson et al., 2007). The amount of magnetic material deposited per unit of surface area varies inversely with the distance from the source. A general assumption is that a rough equilibrium is maintained between particles washed away and new ones deposited (Evans and Heller, 2003). Typically, at $1 \mathrm{~km}$ from the source, the amount of magnetic material is 1 $\mu \mathrm{g} / \mathrm{cm}^{2}$ (Evans and Heller, 2003).

Dry and wet deposition causes particles to reach the hydro-, bio-, and pedosphere (Petrovský and Ellwood, 1999). Dry deposition is the direct incorporation of particles in soil, in the hydrosphere, in vegetation, and on man-made surfaces, 
while wet deposition is the absorption of atmospheric pollutants into droplets followed by droplet precipitation or deposition on Earth's surface (e.g., rain droplets in fog) (Zannetti, 1990). In the hydrosphere, particles accumulate as sediments in rivers, lakes, and oceans. In the pedosphere, particles are incorporated in top soils or accumulate on surfaces. Finally, particles can be resuspended in the atmosphere by wind erosion and sea spray.

\subsection{ATMOSPHERIC POLLUTION—AIRBORNE PARTICLES}

Airborne particulate matter (PM) is, besides ozone (smog), nitrogen oxides (NOx), sulfur oxides (SOx), or, specifically, $\mathrm{SO}_{2}$, carbon monoxide $(\mathrm{CO})$, and lead $(\mathrm{Pb})$, a pollutant for which the Environmental Protection Agency has established air quality standards (Esworthy, 2013). Volatile organic compounds, e.g., PAH, are also counted in the classic pollutants (Holgate et al., 1999). Particulate matter is a mixture composed of solid and liquid particles, both of natural and anthropogenic origin, having diverse chemical and physical characteristics. Particles are classified by their aerodynamic diameter, because it determines transport, removal and deposition processes in the air and on Earth, and pathways within the respiratory tract of the human body (Kim et al., 2015). The typical grain size range for PM covers a few nm to tens of $\mathrm{mm}$. PM is generally separated into (1) coarse particles, smaller than $10 \mu \mathrm{m}$ in aerodynamic

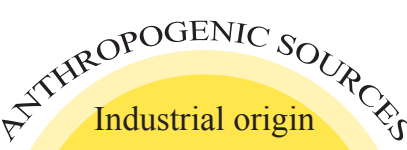

Agricultural origin

Solid fuel combustion

Erosion of pavement

Abrasion of brakes

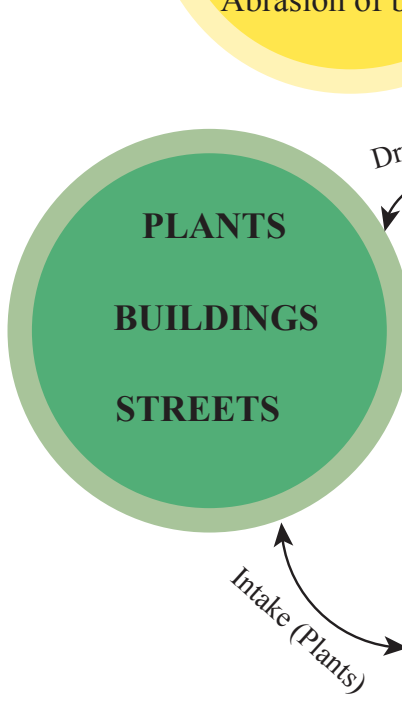

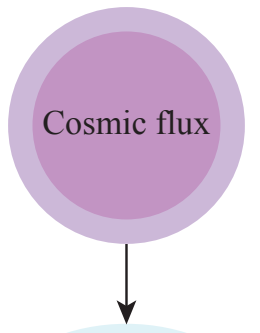

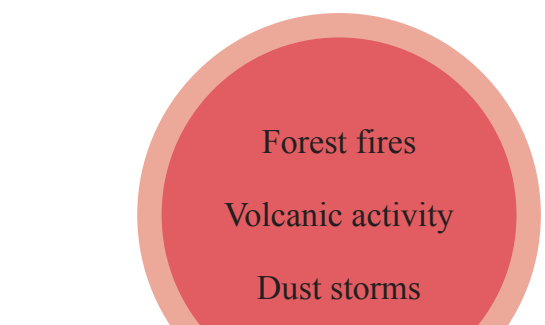

TMOSPHERE

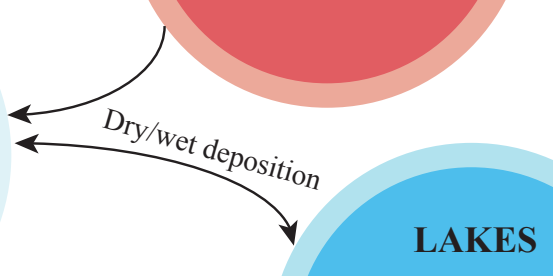

Fly ash 
diameter $\left(\mathrm{PM}_{10}\right)$; (2) fine particles, smaller than $2.5 \mu \mathrm{m}\left(\mathrm{PM}_{2.5}\right)$; and (3) ultrafine particles, which are finer than $0.1 \mu \mathrm{m}\left(\mathrm{PM}_{0.1}\right)$ (Sioutas et al., 2005; Hinds, 1999; Figure 2).

$\mathrm{PM}_{10}$ are inhalable particles that penetrate into the trachea, bronchi, and deep lungs (Figures $2 \mathrm{~b}$ and 3). These particles often correlated with dust originating from paved roads, dirt roads, sites under construction and demolition, mining, industrial processes, agricultural operations and biomass burning. (Esworthy, 2013). $\mathrm{PM}_{10}$ are to a large part mechanically formed by the breakup of larger solid particles, but they also form during combustion processes, such as airborne wastes from industrial processes and motor vehicles (e.g., WHO, 2013, p. 8).

$\mathrm{PM}_{2.5}$ is emitted directly from vehicles, smokestacks, and fires but can also form in reactions in the atmosphere from gaseous precursors, including sulfur oxides, nitrogen oxides, and volatile organics. These precursors occur naturally or in emissions from gasoline and diesel engine exhaust, and in emission from utility and other industrial processes (Esworthy, 2013; Figure 2c). Blanchard (2004) identified the composition of $\mathrm{PM}_{2.5}$ in various sites in the United States, Canada, and Mexico as sulfates, nitrates, ammonium, black and organic carbon, soil, and other particles such as trace metals from fossil fuel combustion and natural bioaerosols. It has been estimated that global emission of $\mathrm{PM}_{2.5}$ is composed half from natural and half from anthropogenic sources (Davidson $e t$ al., 2005).

Particles smaller than a micrometer mainly form through the condensation of metals or organic compounds that are vaporized in high-temperature combustion processes, and by the condensation of gases that have been converted to low-vapor-pressure substances by chemical reactions in the atmosphere (WHO, 2000,
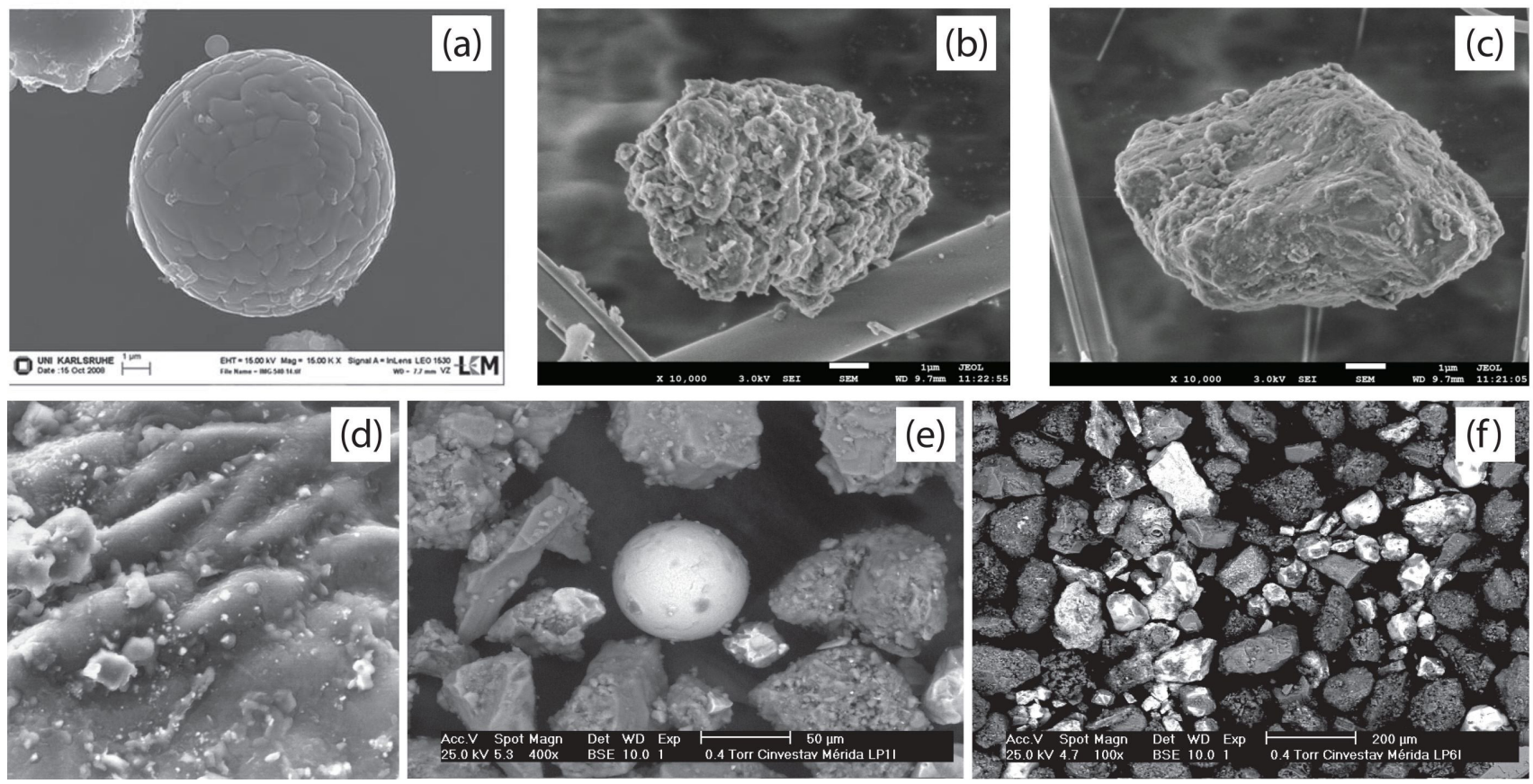

Figure 2 Scanning electron microscope images of anthropogenic particles. (a) Iron oxide fly ash (reproduced from Schleicher et al., 2010, with permission from The Royal Society of Chemistry). (b) $\mathrm{PM}_{10}$ soot particles (reproduced from Wu et al., 2015, licensed under CC-BY-4.0, http://www.mdpi.com/2073-4433/6/8/1 195/htm). (c) $\mathrm{PM}_{2.5}$ soil dust particle (reproduced from Wu et al., 2015, licensed under CC-BY-4.0, http://www.mdpi.com/2073-4433/6/8/1195/htm). (d) Dust on roadside tree (photo by J. Matzka in Maher and Thompson, 1999, with permission from Cambridge University Press 1999; width of micrograph is $60 \mu \mathrm{T})$. (e-f) Urban dust. Spherical and luminous particles are coming from combustion processes and are mainly magnetite (photos by F. Bautista). 
Chapter 7.3). The even-smaller $\mathrm{PM}_{0.1}$ consists of primary combustion products from vehicles, particularly from diesel and automobile exhaust, and includes organic compounds, elemental carbon, and metals (Sioutas et al., 2005).

Particles are further categorized through their origin. Primary PM can originate from natural processes such as aeolian dust, volcanoes, forest fires, living vegetation, and sea spray. Anthropogenic (magnetic) primary PM has its source in fossil fuels (coal and oil combustion in power plants, domestic heating systems, vehicle motors), the abrasion and corrosion of metallic parts (i.e., brakes), the erosion of asphalt roads, iron and steel manufacturing, and agriculture and waste processing plants (WHO, 2013, p. 4). Secondary PM (i.e., ammonium sulphate and nitrate, or sulphuric acids and nitric acids) is formed in the atmosphere and is generally found in small PM (WHO, 2013, p. 3).

Automobile traffic, as a main source of $\mathrm{PM}_{2.5}$ and ultrafine particles in urban sites, has an estimated contribution to $\mathrm{PM}_{2.5}$ of up to $50 \%$ (De Kok et al., 2006). Road transport can be seen as the single most important source of $\mathrm{PM}_{0.1}$ (Holgate $e t$ al., 1999). Pavement abrasion is rich in minerals containing $\mathrm{Si}, \mathrm{Al}, \mathrm{K}, \mathrm{Na}$, and $\mathrm{Ca}$ (Lindbom et al., 2006). Brake and tire particles can contain $\mathrm{Cu}, \mathrm{Sb}$, $\mathrm{Pb}, \mathrm{Cd}$, and Zn (Hjortenkrans et al., 2006). Further pollution-causing sources are direct-exhaust emissions, and iron particles, probably due to carbody rusting also ablation from the exhaust system (Petrovský and Ellwood, 1999). Particles deposited close to the edge of the roads are primarily non-spherical or angular. These particles are of localized significance: beyond distances of 20-30 $\mathrm{m}$, vehicle-derived particles are usually negligible. Inside the roadside band, however, all living beings are exposed to higher concentrations of respirable particles (Petrovský and Ellwood, 1999).

Large amounts of heavy metals are found in fly ashes emitted from coal-burning power plants and industrial smelters (e.g., Petrovský and Ellwood, 1999; Szuszkiewicz et al., 2015). Heavy metals like As, $\mathrm{Cd}, \mathrm{Zn}$, and $\mathrm{Pb}$, and probably also $\mathrm{Br}$, Cr, and $\mathrm{Mn}$, enrich most fly ash and are associated with small respirable particles (Maher and Thompson, 1999). Industrial fly ash also contains iron oxides
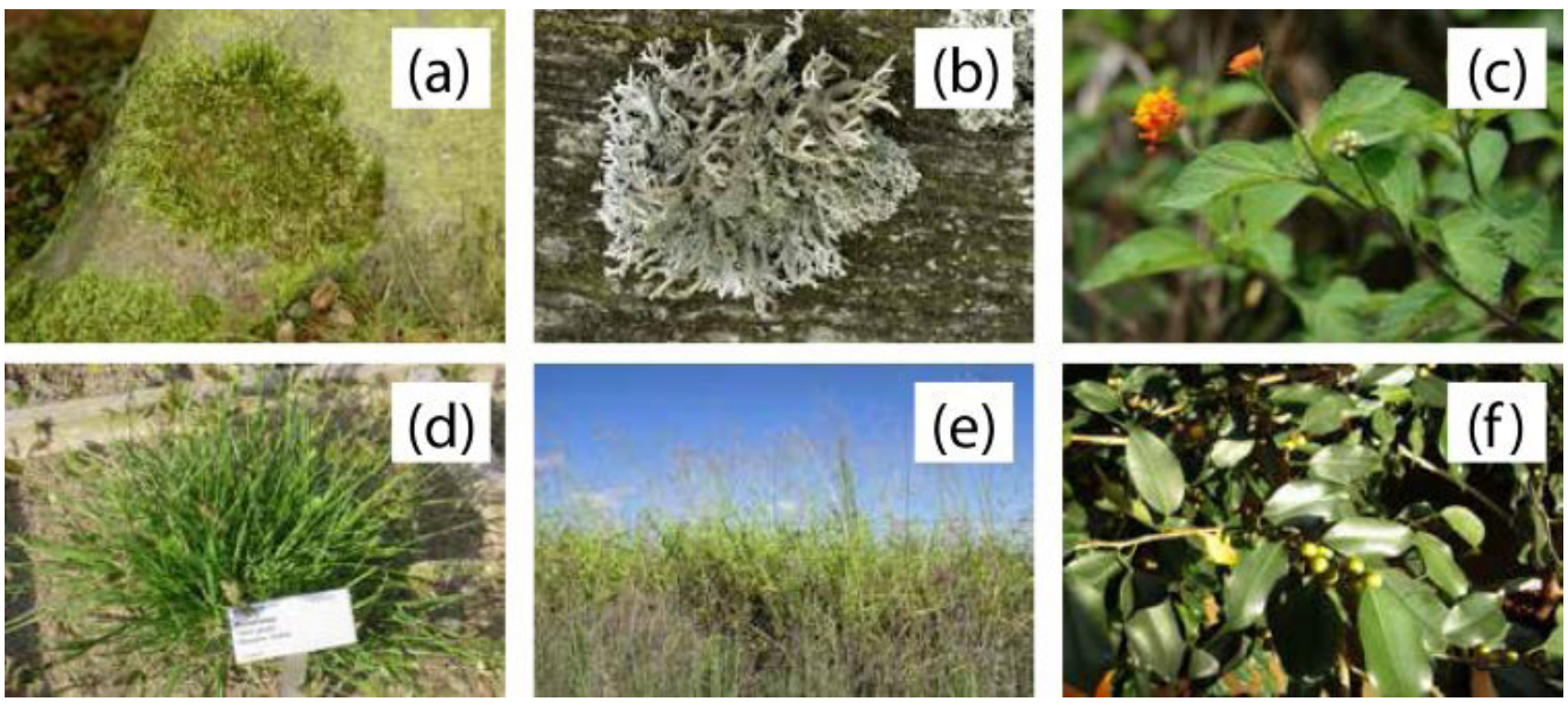

Figure 3 (a) Example of Hypnum cupressiforme and (b) Pseudevernia furfuracea, both by James K. Lindsey (http://www.commanster.eu/ commanster.html) is licensed under CC-BY-SA 3.0. (c) Lantana camara by Franz Xaver (https://commons.wikimedia.org/wiki/User:Franz_ Xaver) is licensed under CC-BY-SA 3.0. (d) Eleusine indica by Daderot (https://commons.wikimedia.org/wiki/User:Daderot) is licensed under the public domain. (e) Panicum maximum by Harry Rose (https://www.flickr.com/photos/macleaygrassman/25136714676/) is licensed under CC-BY-2.0. (f) Ficus benjamina by PauliHartmut is licensed under the public domain. 
such as magnetite and hematite. Magnetite and hematite, as well as maghemite, limonite, and magnesioferrite can be primary minerals. However, magnetite and hematite are formed mainly during the burning process in power plants through the oxidation of pyrite, marcasite, and siderite, but also ankerite and jarosite (Vassilev and Vassilev, 1996; Evans and Heller, 2003). Before being burned, coal is essentially non-magnetic. The combustion causes pyrite to dissociate and form pyrrhotite and sulfur gas. Above $1077^{\circ} \mathrm{C}$ pyrrhotite decomposes into sulfur and iron. In this process spherical iron particles of about $20 \mu \mathrm{m}$ in diameter are formed and subsequently oxidize to magnetite (Evans and Heller, 2003). On average, 16\% of coal burned in a power station becomes ash and about $16 \%$ of this ash is magnetic. In general, the particle size distribution of the burned coal fly ash is defined by the size of the pulverized coal and the temperature of combustion (Flanders, 1999). Furthermore, magnetite and hematite are produced during combustion from clay containing iron in coal through the growth of molten crystals, the reduction of Fe oxide by carbon and hydrogen, and Fe hydroxides dehydroxylation (Vassilev and Vassilev, 1996; Kapička et al., 1999). The processing of steel and the production of cement are further sources of iron oxide minerals (Petrovský and Ellwood, 1999). $\mathrm{Cd}, \mathrm{Cu}, \mathrm{Pb}, \mathrm{Zn}, \mathrm{Cr}$, and $\mathrm{Ni}$ are derived from traffic and industrial emissions, mining, sewage sludge, pesticides, and fertilizers (Wei and Yang, 2010).

Magnetite in fly ash in general appears as discrete rounded grains with a diameter between 1 and $10 \mu \mathrm{m}$, or as dendrites and octahedra in the glass (Petrovský and Ellwood, 1999). Hematite has been found as platy specularite or lamellar crystals, often forming rose-like shapes (Petrovský and Ellwood, 1999). The combustion of fossil fuel raises the concentration of magnetite from 10 ppm in the unburnt fuel to $500-10000 \mathrm{ppm}$ in the combusted fuel; in the case of coal ash the magnetite content may rise up to 160000 ppm (Petrovský and Ellwood, 1999). Coal-fired fly ashes are rich in magnetite with grain sizes ranging from small single domain (SD) to large multidomain (MD) grains, with the largest grain size fraction from 2 to $50 \mu \mathrm{m}$. Magnetite mostly occurs as spherules, sometimes with an "orange peel" surface (Petrovský and Ellwood, 1999; Yang et al., 2007).

\subsection{PLANTS, MOSSES, AND LIGHENS AS REGEPTORS FOR POLLUTANTS}

Tree leaves are considered efficient PM receptors and provide the potential for a large number of samples (e.g., Flanders, 1994; Mitchell et al., 2010; Rai, 2013). Leaves of deciduous species are used for short-term monitoring of PM pollution in urban areas (Matzka and Maher, 1999; Jordanova et al., 2010; Mitchell et al., 2010; Kardel et al., 2011; Hansard et al., 2012; Sadeghian, 2012; Sant'Ovaia et al., 2012; Hofman et al., 2017;), while evergreen species are suitable for longer-term monitoring (e.g., 1-3 years) depending on the leaves' or needles' life-span (Moreno et al., 2003; Urbat et al., 2004). Tree-trunk cores are used for historical or long-term PM monitoring (Zhang et al., 2008; Vezzola et al., 2017).

Kardel et al., (2011) found that deposition of PM on leaves mainly depends on leaf surface area and its surface characteristics. Certain morphological leaf characteristics such as surface roughness due to veins or rugosity and the presence of stellate trichomes favor deposition of PM. Trichomes increase the surface on which atmospheric particles can be deposited, and capture particles from air flowing along the leaf surface (Kardel et al., 2011). Furthermore, ridged, hairy leaves exhibit the greatest deposition capacity (Mitchell et al., 2010). Leonard et al. (2016) investigated PM loads on 16 common native plant species along Sidney roadsides and linked them to their leaf traits such as leaf area, shape, arrangements, as well as the presence of leaf hair. They found that leaves that are broadest below the middle (lanceolate shaped) accumulate more PM than leaves that are narrowest below the middle (obovate and elliptic shaped). Furthermore, they confirmed that plants with leaf hairs accumulated significantly more PM than plants without leaf hairs. Leonard et al. (2016) pointed out that some leaf traits might cancel 
themselves out in terms of PM capturing capacities. Therefore, the combination of different traits has to be taken into account. Hummock-forming plants that are found in peat bogs, have also been shown to trap large amounts of particles due to their shape (e.g., Oldfield et al., 1979).

Mosses and lichens do not possess a root system (Figures 3a and 3b; Hofman et al., 2017). Therefore, nutrients are obtained directly from the atmosphere, along with atmospheric pollution. The absence of the plant cuticle, the protective film covering the epidermis of leaves, allows mosses and lichens to have a higher particle accumulation capacity than leaves (Hofman et al., 2017). Two types of monitoring with mosses can be distinguished: (1) the passive type, using moss that grows naturally in a specific area; (2) the active type, transplanting moss from another location or using moss bags (Ares et al., 2012). The moss bag method, in which mosses are placed in bags to capture pollutants in urban environments where mosses are rare, has been used for the past 40 years (e.g., Goodman and Roberts, 1971; Giordano et al., 2013). An extensive list of plants used in biomagnetic monitoring studies can be found in Rai (2013). Some examples of plants used as biomagnetic monitors are shown in Figure 3.

Tree bark is exposed to pollution year-round and for multiple years (Hofmann et al., 2017). Therefore, trunk bark and branches can exhibit 50-200 times higher magnetization than leaf samples of the same tree (Flanders et al., 1994). Flanders et al. (1994) found that bark can be most effectively sampled with moist tissues. In a magnetic study on Chinese willow (Salix matsudana) tree ring cores, Zhang et al., (2008) found that magnetic particles were present in tree bark and trunk wood. Their measurements of the Scanning Infra-Red Microscope (SIRM) of tree ring cores revealed that tree trunk wood facing the pollution source contained significantly more magnetic particles than other sides of the tree. Therefore, Zhang et al., (2008) suggested that magnetic particles are most likely captured on the bark and then enter into the xylem during the growing season.
Finally, the particles become enclosed into the tree rings by lignification.

\subsection{URBAN SOIL AS REGEPTOR OF POLLUTANTS}

Soil is composed of minerals and organic particles that are arranged in a matrix with about $50 \%$ pore space occupied by water and air (Foth, 1990; Table 1). Soil particles are grouped into different soil, separated according to their particle size and type (Table 1). Stones and gravel, considered part of the coarse fraction of soil, come from the weathering of rocks. They mainly contain minerals of geological origin with small levels of potentially toxic elements. Minerals particles with diameters $<2 \mathrm{~mm}$, smaller than stones and gravels, are considered the fine earth fraction and include sand-, silt- and clay-size particles (Brady and Weil, 2002). Silty sand is a soil mixture separates are often dominated by quartz, but they can also contain significant amounts of feldspar and mica (Foth, 1990). Coarse and fine sands are a mixture of natural particles, which are derived from rock weathering, and of anthropogenic particles. Since sand particles can

Table 1. Type of particles or soil separates with their suggested threshold values.

\begin{tabular}{|c|c|c|}
\hline Particles & $\begin{array}{c}\text { Diameter }\left(\mathbf{U S D A}^{1}\right) \\
(\mathrm{mm})\end{array}$ & $\begin{array}{c}\text { Diameter }\left(\mathbf{W R B}^{2}\right) \\
(\mathrm{mm})\end{array}$ \\
\hline Gravel & $>2$ & \\
\hline Very coarse sand & $0.50-1.00$ & $0.63-1.25$ \\
\hline Coarse sand & $0.25-0.50$ & $0.20-0.63$ \\
\hline Fine sand & $0.10-0.25$ & $0.125-0.200$ \\
\hline Very fine sand & $0.05-0.10$ & $0.020-0.125$ \\
\hline Silt & $0.002-0.063$ & $0.002-0.020$ \\
\hline PM $_{10}$ & $0.0025-0.01$ & \\
\hline $\mathbf{P M}_{2.5}$ & $\leq 0.0025$ & \\
\hline $\mathbf{C l a y}$ & $\leq 0.002$ & $<0.002$ \\
\hline $\mathbf{P M}_{0.1}$ & $\leq 0.0001$ & \\
\hline
\end{tabular}

1 United States Department of Agriculture (USDA): Soil Survey Staff. 1999 Soil taxonomy: A basic system of soil classification for making and interpreting soil surveys. 2nd edition. Natural Resources Conservation Service. U.S. Department of Agriculture Handbook 436.

2 World Reference Base for Soil Resources (WRB): IUSS Working Group WRB. 2015. World Reference Base for Soil Resources 2014, update 2015. International soil classification system for naming soils and creating legends for soil maps. World Soil Resources Reports No. 106. FAO, Rome. 
be carried by the wind, it is necessary to identify their origin. Clays are soil separated $\leq 2 \mu \mathrm{m}$. Due to their very large specific surface they can absorb large quantities of water and other substances than other soil separates (Brady and Weil, 2002). Iron plays a great role in the processes of soil development and affects the physical properties of the soils such as color, structure, and fabric (Maher, 1986). Iron oxides can act as sources or sinks of plant nutrients and pollutants (Maher, 1986). They prevail within soils as discrete fine particles, clusters, or fine-grained material coating other grain or void surfaces (Maher, 1986).

While organic matter is the major coloring agent of soils and is most abundant in surface mineral soil horizons, iron compounds are the most important coloring agents in subsoil horizons, e.g., rusting of iron is an oxidation process that is responsible for the rusty or reddish-colored iron oxide, hematite, in soils (e.g., Bautista et al., 2014). Goethite (FeOOH) produces yellow or yellowish-brown colors, and reduced and hydrated iron oxide has a gray color. The color of the iron oxides is broadly related to the aeration and hydration conditions. However, this is a rather general description. Therefore, each soil has to be characterized diligently, before drawing conclusions on iron oxide or organic matter content from their color (Foth, 1990; Bautista et al., 2014).

Fly ash can be captured in top soils and reveal the pollution history of an area, because soil is able to accumulate particles deposited over a long time range (e.g., Hanesch and Petersen, 1999). Soils have properties that help in the sorption of heavy metals, e.g., the $\mathrm{pH}$ value influences the mobility of heavy metals, organic matter has chelating effects, and clay has a strong sorption capacity (Bautista $e t$ al., 2017). Therefore, soils are classified into substrates with high, medium and low ability to buffer heavy metals (Bautista et al., 2017). In addition, when the buffering capacity of soils is saturated, they become a source of pollutants, with each type of soil being a particular case (Bautista et al., 1999).

The vertical magnetic susceptibility profile of soils reveals that the uppermost soil layers - at around 3-7 $\mathrm{cm}$ depths, but sometimes down to 10 $\mathrm{cm}$ - are most affected by pollution (Rachwal et al., 2017).

\subsection{POLLUTANTS IN URBAN DUST}

Urban dust is a heterogeneous mixture of local soil and dust from natural and anthropogenic sources (e.g., Cortés et al., 2015; Sánchez-Duque et al., 2015). A large portion of the dust is made up of $\mathrm{PM}_{10}$ and smaller particles. As is the case for soils, chemical analyses are costly: they need a large number of samples and may produce toxic byproducts. Besides magnetic methods, the use of colors of urban dust has been suggested by Cortés et al. (2015); e.g, ashes and combustion fumes leave dark colors. An important aspect of the final color of dust is the pretreatment of the samples: sieving, homogenization and humidity content may alter their color (Cortés et al., 2015).

Magnetic minerals found in urban dust and soils are irregularly shaped particles and lacy, vesicular alumino-siliceous spheres $(2-300 \mu \mathrm{m})$ from different industrial sources. The magnetic phases may be irregular non-spherical aggregates of magnetic minerals that are mainly magnetite from vehicle emissions, and pure Fe particles (Bourliva et al., 2017; Zhang et al., 2012).

\subsection{POLLUTANTS GAPTURED IN THE HYDROSPHERE}

Factors that cause deterioration of water quality in coastal areas, estuaries, rivers, and groundwater include industrial waste, domestic sewage, mine drainage, oil spills, agro-chemicals, and destructive fishing techniques. For example, mining exposes heavy metals and sulfur compounds that are leached out of soil by rainwater, resulting in acid mine drainage and heavy metal pollution (Zutshi and Prasad, 2008). Air pollution contributes substantially to water pollution. Mercury, $\mathrm{SO}_{2}$, NOx, and ammonia deposit in water and can cause mercury contamination in fish, acidification of lakes, or eutrophication. $\mathrm{CO}_{2}$ absorbed by the oceans causes an increase in ocean acidification 
(Zutshi and Prasad, 2008). Natural processes that contribute to pollution in the hydrosphere include volcanic activity, rupture of Earth's crust, and river flooding. In freshwater and inland ecosystems, the effect of pollution is obvious on short timescales, whereas pollution in oceans has a large inertia and can be undetected for a long time. Furthermore, pollutants can be transported over long distances (Zutshi and Prasad, 2008).

Membrane filters are useful to collect pollutants directly from the hydrosphere. Scoullos et al. (1979) used a Millipore membrane filter of $0.45 \mu \mathrm{m}$ at various depths for over a year and additionally took sedimentary cores from the same area. They found that the two methods identified similar magnetic minerals. Since heavy metals and magnetic minerals can be captured in river sediments, taking cores of sediments is a useful approach to study the history of pollution (e.g., Zhang et al., 2011). Zhang et al (2011) noticed that sedimentation rates on the riverbed depend on flow velocities. Sedimentation rates were higher where flow rates were lower and the river is broader, e.g., after a strong river bend at Lianshui River, China. High flow velocities cause strong abrasion between the water and the riverbed of coarse and fine particles. Coarse particles, like anthropogenic spherules of sizes 9-14 $\mu \mathrm{m}$, are transported until flow velocities decrease, while small particles can be transported further downstream.

\subsection{THE NEGATIVE EFFECTS OF POLLUTION ON HUMAN HEALTH AND GLIMATE}

Potentially harmful elements, such as heavy metals, can be absorbed in human bodies through inhalation, ingestion, and dermal contact (e.g., Bourliva et al., 2017). Inhalation directly exposes the lungs to airborne metals and is therefore considered a primary route of entry into the body ( $\mathrm{Hu}$ et al., 2012). The size of the particles is a main determinant of where in the respiratory tract they will come to rest when inhaled (Figure 4). Because of their small size, $\mathrm{PM}_{10}$ particles can penetrate the deepest part of the lungs such as the bronchioles or alveoli. Larger particles are generally filtered in the nose and throat via cilia and mucus. The 10 $\mu \mathrm{m}$ size has been agreed upon for monitoring of airborne PM by most regulatory agencies. Similarly, $\mathrm{PM}_{2.5}$ can pass through into the lung and can irritate and corrode the alveolar walls (Xing et al., 2016). Ultra-fine particles may be more dangerous than larger particles, on the one hand, because of dosimetric effects, and on the other hand, they may serve as catalysts for reactions with cells because of their larger surface area per given mass (Oberdörster, 2001). Furthermore, ultrafine particles may pass through the lungs and reach the blood circulation and further into extrapulmonary tissues and organs (Oberdörster, 2001).

Besides inhalation, PM is ingested via deposition on food, drinks, and indoor and outdoor surfaces and soil (e.g., Hu et al., 2012; Salmani-Ghabeshi et al., 2016). Although higher levels of potentially toxic minerals were found in the atmosphere than in urban soils (Hu et al., 2012), $\mathrm{Hu}$ et al. (2012) showed that ingestion of certain

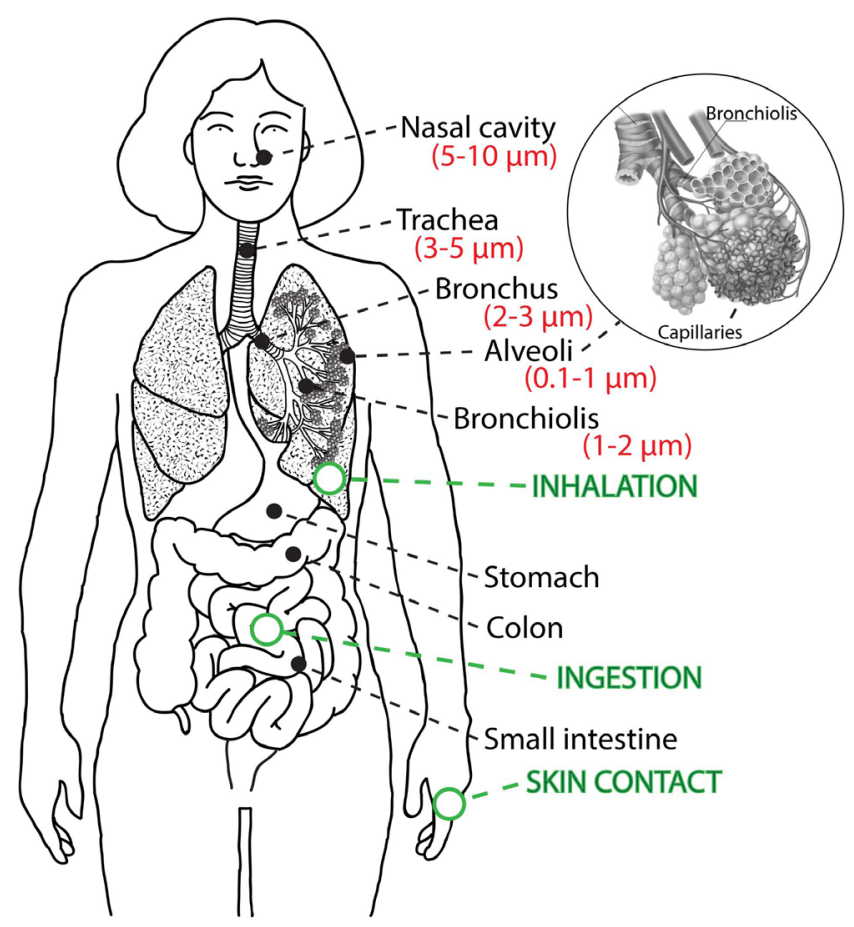

Figure 4 Pathways of intake of particulate matter: inhalation through the respiratory system and particle size in brackets, ingestion through the digestive system and intake through skin contact. 
heavy metals poses higher carcinogenic risks than their inhalation. For example, Qu et al. (2012) showed in a study about a lead-zinc mining area in China, that for each heavy metal, different exposure pathways make different contributions. For example, $\mathrm{Pb}$ is absorbed in the human body mainly through ingestion via the deposition on soil, but also through indoor air inhalation and ingestion of vegetables, specifically of pak choi. Heavy metals attach tightly to the leaf surface, and especially pak choi accumulates high quantities of pollutants. Correspondingly, Hu et al. (2012) found inhalation the most important pathway of intake for $\mathrm{Hg}$. Additionally, the distance from the pollution source changes the importance of each exposure pathway. For example, in the village closest to the lead-zinc mine Cd was mainly absorbed via soil dermal contact and inhalation.

Health risk of heavy metals via dermal contact arises through skin absorption in the shower, by washing hands with contaminated water, or while swimming (e.g., Li et al., 2018). Few studies report on the risks of absorption via dermal contact, with many of them claiming no or a low health risk through the skin pathway. $\mathrm{Hu}$ et al. (2012) investigated aerosols, collected from urban and suburban sites in China and found carcinogenic risks of As, Cd, Co, Cr and Ni via dermal contact and inhalation within the acceptable limits. However, the pathway vial dermal contact can be of higher health risk when considering street dust. Zheng et al. (2010) examined the heavy metal contamination found in street dust arising from metal smelting in the industrial district of Huludao City, China. Their findings revealed that ingestion of the dust particles turned out to be the exposure pathway with highest health risk, followed by dermal contact. On the contrary, inhalation of street dust posed a negligible risk.

Although heavy metals can support normal biological functions of cells, their toxicity involves damage primarily to liver, central nervous system, DNA, and kidney in animals and humans (Sharma et al., 2014). Over 3 million deaths through cardiovascular disease occur globally each year as direct consequence of air pollution of PMs (Shah et al., 2015). Exposure to PM is a source of various health problems such as premature death in people with heart or lung disease, nonfatal heart attacks, irregular heartbeat, aggravated asthma, decreased lung function, and increased respiratory symptoms, e.g., irritation of airways, coughing, difficulty of breathing, and damage to neurological and reproductive systems (e.g., Curtis et al., 2006; Kim et al., 2015). Air pollution is associated with large increases in medical expenses and morbidity, and is estimated to cause about 800000 annual premature deaths worldwide (Curtis et al., 2006). Approximately $3 \%$ of cardiopulmonary deaths and $5 \%$ of lung cancer deaths are attributable to PM globally (WHO, 2013). Some studies have found increases in respiratory and cardiovascular problems at outdoor pollutant levels well below standards set by such agencies as the US EPA and WHO. Nowadays, PM pollution is estimated to cause 22000-52000 deaths per year in the United States (Mokdad et al., 2004) and 190000 deaths per year in Europe (WHO, 2016, p. 40). Pope III et al. (1992) first pointed out that in Utah, death rose in proportion to airborne particles less than $10 \mathrm{~mm}$ in size; they estimated that a concentration of 100 $\mathrm{mg} / \mathrm{cm}^{3}$ increased the death rate by $16 \%$.

Especially in terms of long-term exposure, $\mathrm{PM}_{2.5}$ is a stronger risk factor than $\mathrm{PM}_{10}$. The risk of cardiopulmonary mortality increases by $6-13 \%$ per $10 \mu \mathrm{g} / \mathrm{m}^{3}$ (WHO, 2013). $\mathrm{PM}_{2.5}$ may lead to high plaque deposits in arteries, causing vascular inflammation and atherosclerosis - a hardening of the arteries that reduces elasticity, which can lead to heart attacks and other cardiovascular problems. Dominici et al. (2006) found a short-term increase in hospital admission rates associated with $\mathrm{PM}_{2.5}$. The largest association was for heart failure, which had a $1.28 \%$ (95\% confidence interval, $0.78 \%-1.78 \%$ ) increase in risk per $10 \mu \mathrm{g} / \mathrm{m}^{3}$ increase in same-day $\mathrm{PM}_{2.5}$ (Dominici et al., 2006). An increased risk of cardiac arrest in time-series and case-crossover analysis for a $\mathrm{PM}_{2.5}$ increase of $10 \mu \mathrm{g} / \mathrm{m}^{3}$ on the average of $0-$ and 1 -day lags was found. Associations of cardiac arrest with other 
pollutants were weaker. These findings, consistent with studies implicating acute cardiovascular effects of PM, support a link between $\mathrm{PM}_{2.5}$ and out-of-hospital cardiac arrests. Since few individuals survive an arrest, air pollution control may help prevent future cardiovascular mortality (Silverman et al., 2010).

PMs related to combustion are most hazardous to health. The black-carbon part of $\mathrm{PM}_{2.5}$ has detrimental effects on health as well as on climate. Components of PM attached to black carbon are, for example, polycyclic aromatic hydrocarbons $(\mathrm{PAH})$ that are known carcinogens and directly toxic to cells, as well as metals and inorganic salts. Exhaust from diesel engines has been classified as carcinogenic (WHO, 2013). Also, Rohr and Wyzga (2012) reviewed studies on health effects of individual PM constituents and determined that carbon-containing PM components (elemental and organic carbon) are most strongly associated with adverse health effects.

Iron oxides, as carriers of heavy metals, are no more than a fraction of the total amount of pollutants, but there is evidence that they can be a health risk, especially the smaller grain sizes (Garçon et al., 2000; Evans and Heller, 2003; Gieré et al., 2006; De Kok et al., 2006; Maher et al., 2016; Song et al., 2016). Nano- to micrometer sized magnetic iron oxides may induce oxidative stress pathways, free radicals' formation, and DNA damage (Hofman et al., 2017). For example, magnetite may provoke toxic effects on human lung cells.

Particulate matter in the atmosphere contributes to the generation of thermal inversion, which results in heat islands in the cities (Pandey et al., 2012). It also affects visibility. For example, an object can seem to be $200 \mathrm{~km}$ away or more in clean, dry air, but polluted air can restrict visibility to less than $1 \mathrm{~km}$ (Davidson et al., 2005). Furthermore, Malm (2003) reports that reduced visual range can have a marked influence on the psychological well-being of people, increasing stress and degrading the enjoyment of outdoor leisure activities. Aerosols influence the climate directly by scattering and absorbing radiation (Fuzzi et al., 2015). Furthermore, an increase in anthropogenic aerosols causes an increase in cloud droplets resulting in a larger amount of solar radiation being reflected back to space (Fuzzi et al., 2015).

A consequence of pollution in the oceans is the accumulation of pollutants in the bodies of marine animals, such as shellfish. Animals and humans that eat the polluted shellfish have a greater health risk. Contaminants in water are especially dangerous because they are ingested by oral and dermal route (Zutshi and Prasad, 2008).

\section{Magnetic minerals in anthropogenic pollution agents}

Ferromagnetic (s.l.) minerals can easily be detected in natural samples through mostly non-destructive environmental magnetic measurements. These kinds of minerals can have a variety of natural and anthropogenic sources (Cornell and Schwertmann, 2003). A summary of the most important ferromagnetic minerals and their characteristics can be found in Table 2 .

The Curie temperature $\left(\mathrm{T}_{\mathrm{c}}\right)$ or Neel temperature $\left(\mathrm{T}_{\mathrm{N}}\right)$ in antiferromagnetic minerals, is the temperature at which the mineral changes to a paramagnetic state. At this temperature the mineral loses all its magnetization and magnetic susceptibility, because thermal energy is larger than magnetic exchange interaction. This temperature is characteristic for each ferromagnetic (s.l.) mineral (Figure 5).

By gradually lowering the temperature below $\mathrm{T}_{\mathrm{c}}$, the thermal energy overcomes the magnetic anisotropy until the remanent magnetization blocks in at the blocking temperature $\left(\mathrm{T}_{\mathrm{b}}\right)$. With increasing grain size, $\mathrm{T}_{\mathrm{b}}$ approaches $\mathrm{T}_{\mathrm{c}}$. Natural samples usually have a broad grain size distribution so that the maximum $\mathrm{T}_{\mathrm{b}}$ is often equivalent to $\mathrm{T}_{\mathrm{c}}$ (Liu et al., 2012). Through the substitution of iron with titanium, saturation magnetization $\mathrm{M}_{\mathrm{s}}$ decreases and $\mathrm{T}_{\mathrm{c}}$ decreases nearly linearly (Evans and Heller, 2003). 
Table 2. Ferromagnetic (s.l.) minerals found in particulate matter and their magnetic characteristics. Tc Curie temperature, Tn Neel temperature, Ms saturation magnetization. * Tc in brackets, temperature range are inversion temperatures. AFM: Antiferromagnetic, FiM: Ferrimagnetic, FM: Ferromagnetic (s.s.), ${ }^{1}$ Verwey transition, ${ }^{2}$ Morin transition.

\begin{tabular}{|c|c|c|c|c|c|c|}
\hline Mineral & Magnetite & Hematite & Maghemite & Goethite & Pyrrhotite & Greigite \\
\hline Formula & $\mathbf{F e}_{3} \mathrm{O}_{4}$ & $\boldsymbol{\alpha}-\mathrm{Fe}_{2} \mathrm{O}_{3}$ & $\boldsymbol{\gamma}-\mathrm{Fe}_{2} \mathrm{O}_{3}$ & $\boldsymbol{\alpha}$-FeOOH & $\mathbf{F e}_{7} \mathrm{~S}_{8}$ & $\mathbf{F e}_{3} \mathrm{~S}_{4}$ \\
\hline Type of magnetism & FiM & spin canted AFM & FiM & AFM, FM & FiM \\
\hline Tc or Tn ( $\left.{ }^{\circ} \mathbf{C}\right)$ & $580,-150^{1}$ & $675,-15^{2}$ & $(645) ; 250-900^{*}$ & 120 & 320 & 330 \\
\hline Ms (kA/m) & 480 & 2.5 & 380 & 2 & 80 & 125 \\
\hline Color & Black & Red & Reddish-brown & Yellow-brown & Dark brown & Blue-black \\
\hline
\end{tabular}

Magnetite is one of the most common ferromagnetic (s.l.) minerals found in natural samples. It appears totally opaque in microscope thin sections. Its high spontaneous magnetization $\left(\mathrm{M}_{\mathrm{s}}\right)$ makes it the most magnetic naturally occurring mineral. Ti-magnetite is naturally formed in a variety of igneous rocks; as a result of weathering and erosion the minerals find their way into the natural cycle. Hematite is an iron oxide common in soils and sediments. Its spontaneous magnetization is about 200 times weaker than magnetite. It is, nevertheless, thermally more stable than magnetite due to its higher $\mathrm{T}_{c}$. Below the Morin transition at $-15^{\circ} \mathrm{C}$, hematite loses its magnetization (Evans and Heller, 2003). Maghemite occurs widely in soils and its chemical formula is simility to that of hematite, but with a different crystallographic structure. Maghemite is fully oxidized magnetite and has the same cubic structure. The spontaneous magnetization is slightly lower than that of magnetite. The $\mathrm{T}_{\mathrm{c}}$ is often stated as around $645^{\circ} \mathrm{C}$, but $\mathrm{T}_{\mathrm{c}}$ of maghemite is experimentally difficult to determine because maghemite is thermally metastable. At increased temperatures, between 200 and $900^{\circ} \mathrm{C}$, its crystallography irreversibly changes to hematite. This inversion temperature depends on impurities in the crystallographic lattice and grain sizes (Evans and Heller, 2003). Goethite is an iron oxyhydroxide with a hexagonal structure. Magnetic iron sulphides like Goethite are commonly found in reducing (anoxic) environments (estuarine mud), where organic matter is consumed by bacteria in the absence of oxygen (Rai, 2013). Zheng and Zhang (2008) observed
Goethite in street dust and topsoil samples from Beijing. Its occurrence was evidenced in a peak around $280-300^{\circ} \mathrm{C}$ in thermomagnetic curves that indicated the transformation from goethite to maghemite.

Iron sulfides such as pyrrhotite and greigite have become of great importance in studies of environmental pollution, because they act as "sinks" for toxic heavy metals (Dekkers and Schoonen, 1994; Snowball and Torii, 1999;). Pyrrhotite occurs naturally as an authigenic component in relatively old rocks, in present-day marine environments, in deep-sea cores, and in terrestrial sequences (Snowball and Torii, 1999). Greigite is commonly found in nature in ore deposits, lake sediments, and soils, or is formed in bacteria. Metallic iron, mixed with magnetite, has been found in indoor dust samples from apartments in the city center Zyrardow situated south-west of Warsaw, Poland (Górka-Kostrubiec and Szczepaniak-Wnuk, 2017). The metallic iron was mainly identified through its Tc of around $770^{\circ} \mathrm{C}$. Iron was also observed in Chinese street dust samples, but not in topsoil samples from the same locations (Zheng and Zhang, 2008). The absence of elemental iron in the topsoil samples was interpreted by the transformation of iron into iron-containing minerals by redox or other chemical reactions with organic matter. Muxworthy et al. (2002) combined magnetic measurements and Mössbauer spectroscopy on dust samples collected in Munich, Germany. Both methods identify a maghemite-like phase and an iron/maghemite phase, which they interpreted as an independent maghemite phase and a metallic iron phase with 


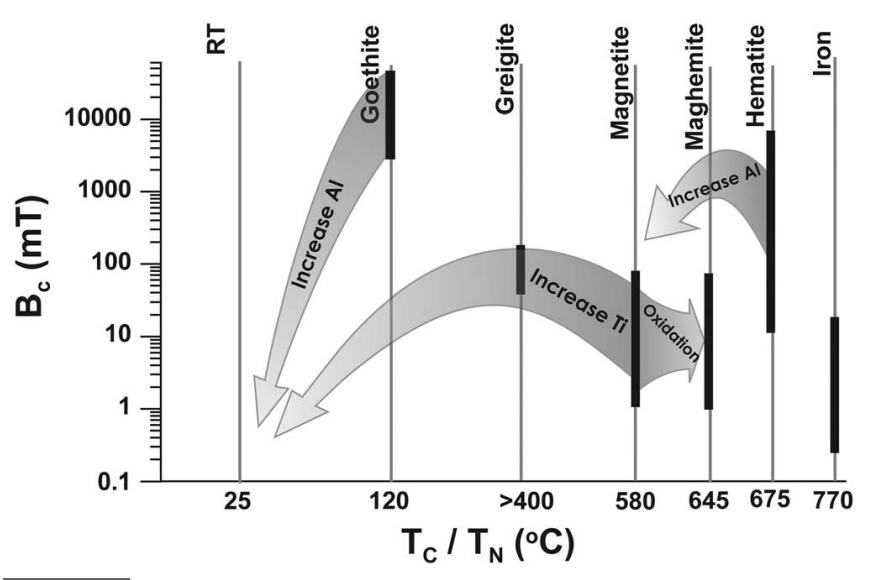

Figure 5 A schematic correlation of coercivity, $B_{c}$, with Curie temperature, $T_{c}$, and Neel temperature, $T_{N}$, for different magnetic minerals. Arrows indicate the effects of isomorphous substitution and oxidation on the corresponding magnetic properties of these minerals. The thicker lines indicate coercivity ranges for different minerals. RT indicates room temperature. Figure taken from Liu et al. (2012).

a maghemite shell. Maghemite was attributed to automobiles, whereas the metallic iron to electric street-trams, which closely pass by the sampling site.

The metallic iron content constitutes about $1 \%$ of urban atmospheric PM, of which $10-70 \%$ is made up of iron oxides and hydroxides (Muxworthy et al., 2002). Large amounts of this iron are attributed to mobile sources, such as vehicles. Moreover, iron impurities in fossil fuel convert during combustion to magnetic iron oxides, i.e. magnetite, maghemite, hematite, or a mixture, depending on the combustion conditions.

The combustion of coal is one of the anthropogenic sources of magnetic fly ash. In an experiment, Liu et al. (2017) combusted iron-bearing coal at different temperatures and investigated its transformation behavior and the magnetic characteristics of the fly ash. During the combustion process, pyrite and siderite transform into iron oxides. They found that with increasing temperatures the relative content of magnetite and maghemite decreases, while hematite increases. In topsoil next to a road, Hoffmann et al. (1999) found that magnetite is the principal magnetic mineral for the enhancement of magnetic susceptibility.
This magnetite is believed to mainly arise from abrasion products from asphalt and from vehicle brake systems.

Kopcewicz and Kopcewicz (2001) investigated iron compounds of aerosols in Poland using Mössbauer spectroscopy. They found a significant amount of iron sulfides $\left(\mathrm{FeS}_{2}, \mathrm{FeS}_{2} \mathrm{Fe}_{1}-\mathrm{xS}\right)$ in winter, which they attributed to combustion of coal from house heating. Furthermore, they identified iron oxyhydroxides and iron oxides, mostly $\alpha-\mathrm{Fe}_{2} \mathrm{O}_{3}$, originating from automobile exhaust.

\section{Magnetic parameters}

Magnetic parameters give insight into the domain state and grain size, the magnetic mineralogy, and the concentration of magnetic minerals in the sample. Detailed explanations of the physical background of magnetization and different domain states has previously been published (Thompson and Oldfield, 1986; Dunlop and Özdemir, 1997; Evans and Heller, 2003).

\subsection{MAGNETIC SUSGEPTIBILITY}

Magnetic susceptibility is one of the most commonly used mineral magnetic parameters. It is the ratio of induced magnetization $(\mathbf{M}$, dipole moment per unit volume or $\mathbf{J}$, dipole moment per unit mass) to the applied weak magnetic field $(\mathbf{H})$ and expresses the capability of a material to be magnetized under the effect of an external magnetic field. Only for isotropic substances the induced magnetization is strictly parallel to the applied field, and the magnetic susceptibility is a scalar. In the general case of anisotropic media, like minerals and rocks, the induced magnetization is not parallel to the applied field, and the magnetization induced along the direction $i$ is related to the magnetic field acting along the direction $j$ by:

$$
\mathrm{J} i=\chi \dot{j} \mathrm{H} j \text { (mass specific) } \quad \chi \mathrm{m}^{3} / \mathrm{kg}
$$
or

$\mathrm{M} i=\mathrm{k} i j \mathrm{H} j$ (volume specific) $\quad \mathrm{k}$ is dimensionless 
Magnetic susceptibility mostly depends on the concentration and grain size of ferromagnetic (s.l.) as well as the contribution of para- and diamagnetic particles in a rock. For magnetite, magnetic susceptibility at low frequencies $\left(\mathrm{k}_{\mathrm{If}}\right.$ or $\left.\chi_{\mathrm{If}}\right)$ is remarkably constant over a wide range of grain sizes; it is, however, particularly sensitive

to magnetite ultrafine magnetite particles, e.g, superparamagnetic (SP) particles in the 0.01-0.03 $\mu \mathrm{m}$ grain-size range. The frequency dependence can be used to detect these very small grains (Forster et al., 1994; Dearing et al., 1996). The frequency dependence of magnetic susceptibility $\left(\mathrm{k}_{\mathrm{fd}}\right.$ or $\left.\chi_{\mathrm{If}}\right)$, using magnetic susceptibility at low and high frequency $\left(\mathrm{k}_{\mathrm{lf}}\right.$ or $\chi_{\mathrm{lf}}$ and $\mathrm{k}_{\mathrm{hf}}$ or $\chi_{\mathrm{hf}}$, respectively, is defined as $\mathrm{k}_{\mathrm{fd}}=\left(\left(\mathrm{k}_{\mathrm{lf}}-\mathrm{k}_{\mathrm{hf}}\right) / \mathrm{k}_{\mathrm{lf}}\right) \times 100 \%$. At a low frequency $\omega$, corresponding to a period, $1 / \omega$, larger than the relaxation time $(1 / \omega>\lambda)$, SP grains contribute strongly to the susceptibility. Whereas the same grain becomes SD at high frequencies corresponding to a period smaller than the relaxation time $(1 / \omega<\lambda)$. At a low frequency, SP grains equilibrate and can have higher susceptibilities than single domain (SD) grains. It is suggested that samples with $\mathrm{k}_{\mathrm{fd}}>10 \%$ have dominating contribution of SP particles (Dearing et al., 1996). The frequency dependence of magnetic susceptibility reflects the concentration of SP grains, and particularly those close to the threshold SP-SD, that is 0.015-0.025 $\mu \mathrm{m}$ for magnetite (Maher, 1988). SD particles are extremely stable carriers of remanent magnetization with frequency-independent magnetic susceptibilities. In contrast, SP particles just below the blocking volume of $\mathrm{SD}$ are unable to retain a stable remanence, but their susceptibilities are highly frequency dependent. The actual magnetic behavior of ultrafine magnetic particles, i.e., the observation of a SP or blocked state, largely depends on the value of measuring time $\left(\mathrm{t}_{\mathrm{m}}\right)$ of the specific experimental technique with respect to the relaxation time (t) (Wang et al., 2010). Figure 6 shows an example of frequency-dependent magnetic susceptibility at a college in Jalingo, Nigeria. Values of $\chi_{\mathrm{FD}}>10 \%$ indicate a large contribution of SP particles. The scattergram shows that the largest contribution to magnetic susceptibility is due to SP ferromagnetic grains $<0.05 \mu \mathrm{m}$ (Kanu et al., 2014).

Continuous thermomagnetic curves, which are magnetic susceptibility or saturation magnetization versus temperature ( $\chi-T$ or $M_{s}-T$ curves), in a saturation field of $1 \mathrm{~T}$, are measured to determine the predominant magnetic minerals in the sample and their thermal stability (Goguitchaichvili et al., 2001). For the high-temperature curves, samples are usually heated to temperatures up to $700^{\circ} \mathrm{C}$ and subsequently cooled to room temperature, while the magnetic susceptibility or magnetization is monitored. Commonly, the Curie temperature, which is typical for each magnetic mineral, is determined from the heating curve. The thermal stability is highest if heating and cooling curves overlap completely. The low-temperature thermomagnetic curves $\chi-T$ are measured while the sample is heated from temperatures as low as about $-196^{\circ} \mathrm{C}$ to room temperature. An example of low- and high-temperature thermomagnetic curves is shown in Figure 6 for four different materials (Sagnotti et al., 2009). In the low-temperature thermomagnetic curve an increase with maxima at $-60^{\circ} \mathrm{C}$ for the brake sample (Figure $7 \mathrm{~b}$ ) and at -30 to $-50^{\circ} \mathrm{C}$ for the other specimens was observed. In the high-temperature part of the thermomagnetic

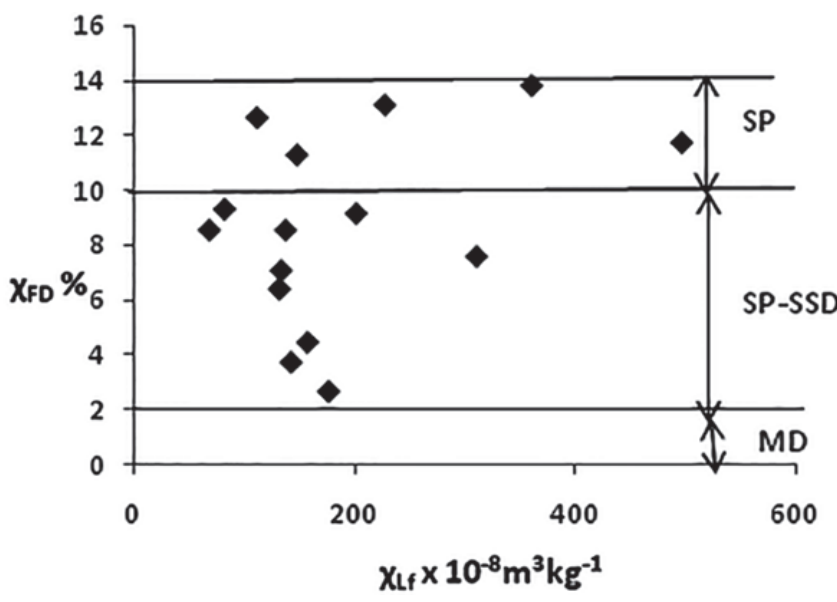

Figure 6 A schematic $\chi_{\mathrm{If}}{ }^{-} \chi_{\mathrm{fd}} \%$ scattering diagram showing samples from Jalingo College of Education, Nigeria (reproduced from Kanu et al., 2014, licensed under CC-BY-NC-ND 4.0, https://www. sciencedirect.com/science/article/pii/S0016716914700753). 
curves a $\mathrm{T}_{c}$ of $\sim 580^{\circ} \mathrm{C}$ was observed in the heating curve for all specimens, indicating magnetite as the main magnetic mineral.

\subsection{MAGNETIC HYSTERESIS, DAY PLOT, AND FIRST- ORDER REVERSAL GURVES}

Magnetic hysteresis is a property of all ferromagnetic (s.l.) minerals, causing the magnetization of such a material to be strongly dependent on its magnetic history. The magnetization of a material is measured in dependence of an increasing and decreasing magnetic field. Parameters obtained from hysteresis loops are the saturation magnetization $\left(\mathbf{M}_{\mathrm{s}}\right)$, remanent saturation magnetization $\left(\mathbf{M}_{\mathrm{rs}}\right)$, and coercivity $\left(\mathbf{B}_{\mathrm{c}}\right)$ (Figures $8 \mathrm{a}$ to $8 \mathrm{c}$ ). Another approach to detect SP particles, besides the frequency dependence of magnetic susceptibility, is through measurements of hysteresis loops at very low temperatures. At low temperatures, SP particles behave like SD particles and can retain a remanence that is visible in the hysteresis loop (Radhakrishnamurty et al., 1971). However, these particles are not necessarily the same as those responsible for large $\chi_{\mathrm{fd}}$.

The Day plot (Day et al., 1977; Dunlop, 2002a; $2002 b$ ) shows $\mathrm{M}_{\mathrm{r}} / \mathrm{M}_{\mathrm{rs}}$ versus $\mathrm{B}_{\mathrm{cr}} / \mathrm{B}_{\mathrm{c}}$, with $\mathrm{B}_{\mathrm{cr}}$ the remanence of coercivity obtained from the backfield curve measurement (application of an opposed incremental magnetic field). The Day plot, defined for magnetite only, indicates the grain size range of the magnetic minerals (Figure 8d).

First-order reversal-curve (FORG) diagrams are used to detect grain size distributions and can reveal signatures of SP particles (Pike et al., 1999). FORC diagrams make it possible to define the detailed coercivity distribution of the magnetic particles and their interaction field strengths. FORCs are a series of partial hysteresis loops made after the sample magnetization is saturated in a large positive applied field. To better visualize the produced set of loops, they are transformed into contour plots by calculating the second derivative of the measured magnetization, usually referred to as FORC diagrams (Figure 8e).
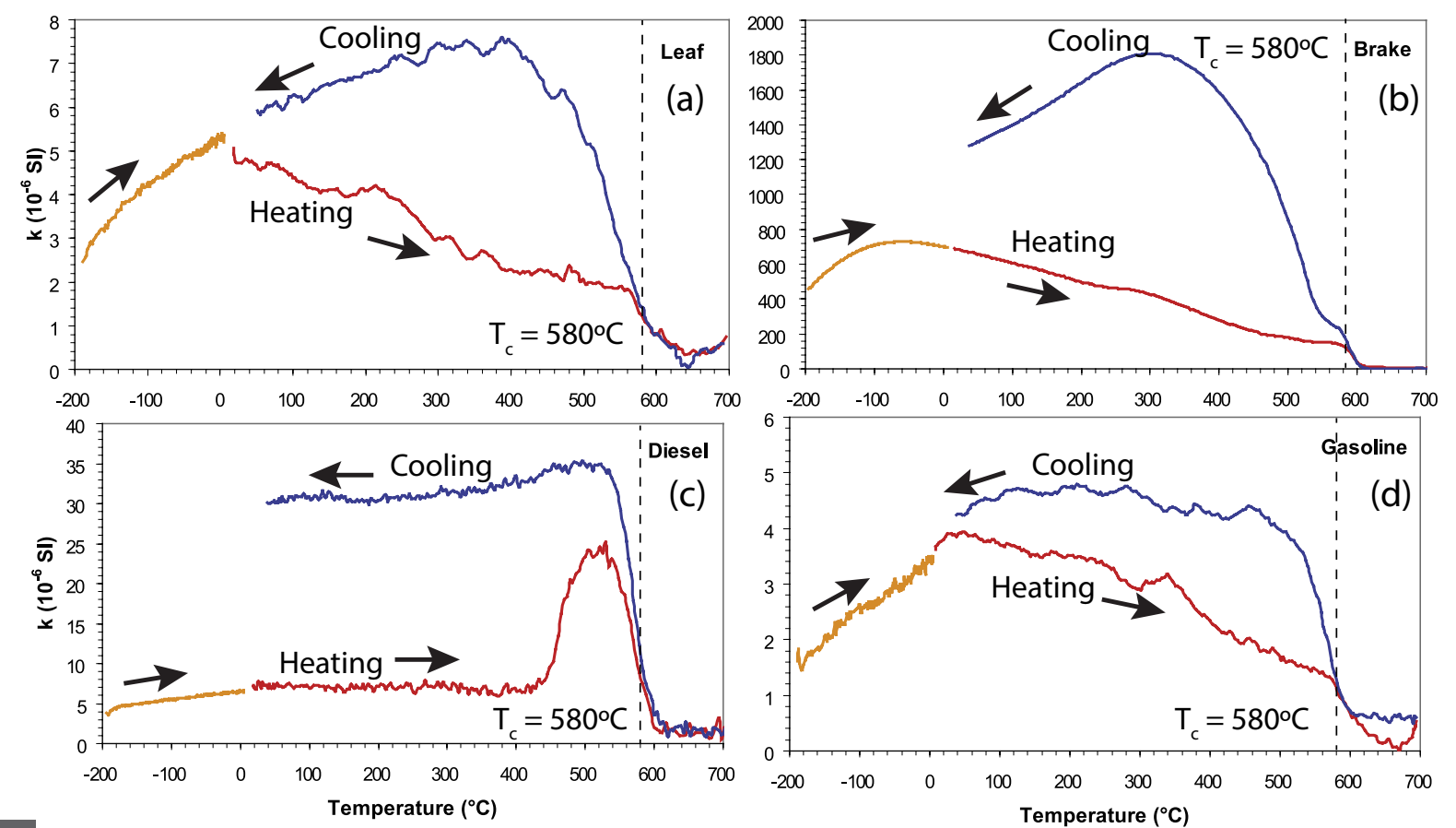

Figure 7 Thermomagnetic susceptibility curves for the four types of specimens, showing the changes in volume magnetic susceptibility during heating back to room temperature after cooling to liquid nitrogen temperature (orange) and during a heating (red)-cooling (blue) cycle from room temperature to $\sim 700^{\circ} \mathrm{C}$. The high-temperature cycle was measured in an argon atmosphere (modified after Sagnotti et al., 2009). 

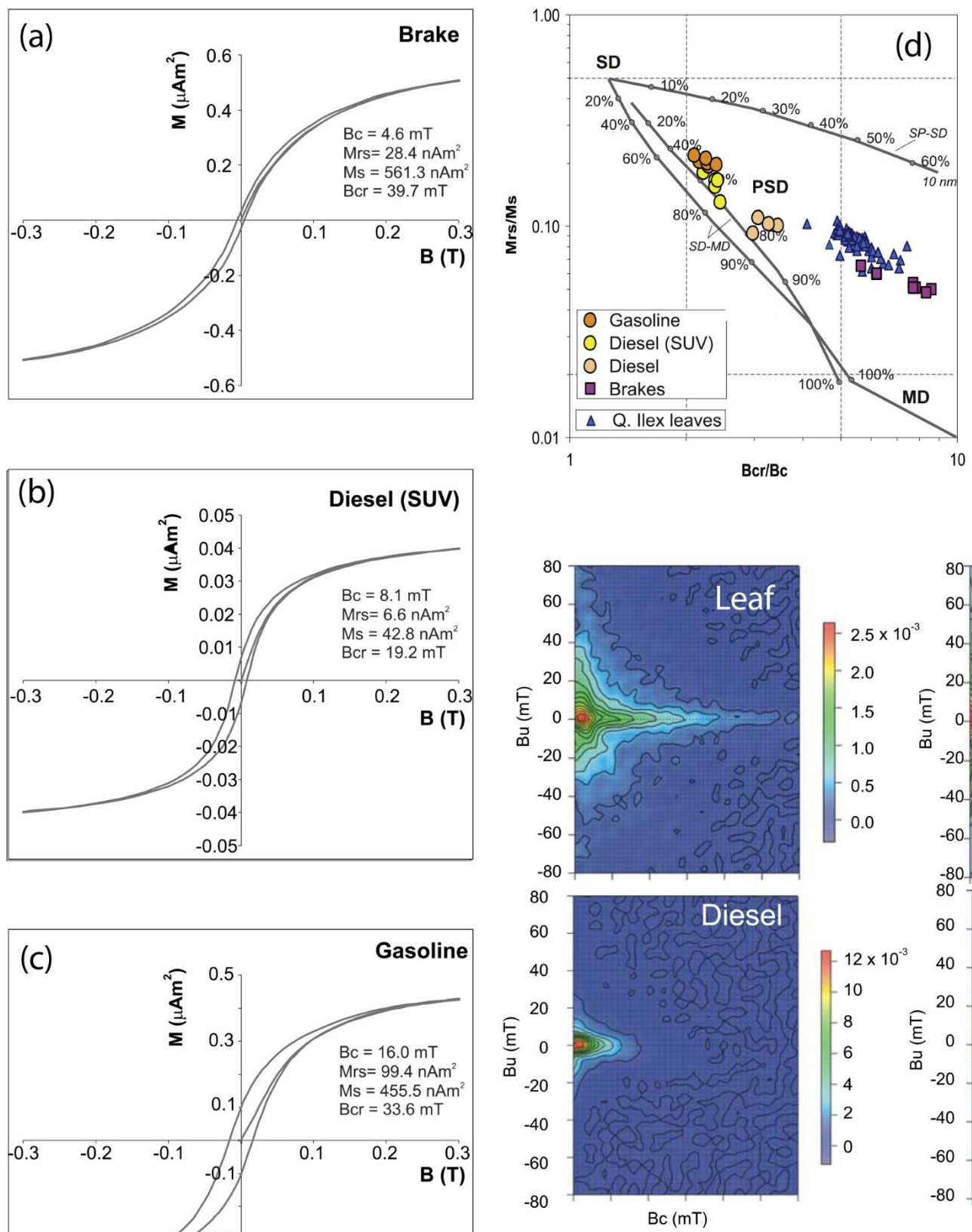

(e)
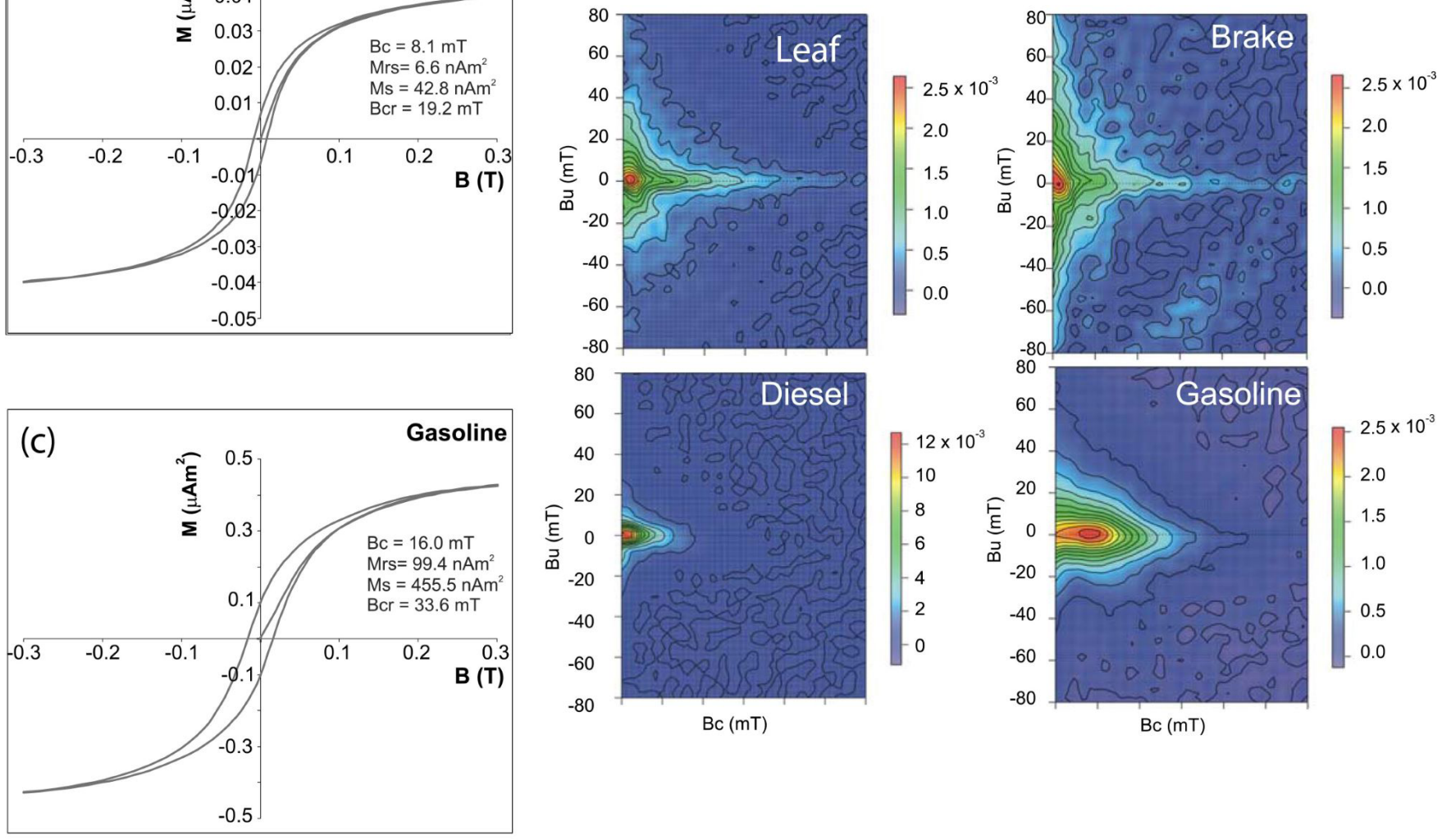

Figure 8 (a-c) Hysteresis curves. (d) Day plot. (e) First Order Reversal Curves (FORCs) (modified after Sagnotti et al., 2009). 


\subsection{TYPES OF REMANENT MAGNETIZATION}

Remanent magnetization is the magnetization that remains in a ferromagnetic (s.l.) mineral after removing a magnetic field. On the contrary, dia- and paramagnetic minerals cannot retain a remanent magnetization. Natural remanent magnetization (NRM) is obtained through natural processes, whereas other types of remanent magnetizations can be imparted in the laboratory in order to gain information about the ferromagnetic (s.l.) carriers of the samples.

Anhysteretic Remanent Magnetization (ARM) is the magnetization produced by the simultaneous employment of an alternating magnetic field (AF) and a direct current (DC) field. The magnitude of $\mathrm{ARM}$ depends on the applied $\mathrm{AF}$ and DG fields (Liu et al., 2012). Usual values of AF fields are 100 $\mathrm{mT}$ and DC fields are $50 \mu \mathrm{T}$.

All magnetic particles with coercivity lower than the maximum applied AF will remain aligned parallel with the direction of the bias field. The ARM intensity depends mostly on the concentration of fine $\mathrm{SD}$ particles. ARM is proportional to the DC bias field, and therefore, the anhysteretic susceptibility $\left(\chi_{\text {ARM }}\right)$ is defined as the ratio of ARM over the bias magnetic field, $\left(\chi_{\text {ARM }}=\right.$ ARM/DC bias field; e.g., Liu et al., 2012). The $\chi_{\text {ARM }}$ is strongly dependent on magnetic particle concentrations. Therefore, ARM can decrease with increasing concentration as shown on SD magnetite by Sugiura (1979).

In order to differentiate grain sizes of magnetite, Banerjee et al. (1981) suggested plotting the specific ARM (or $\chi_{\text {ARM }}$ ) versus low field $\chi$. The magnitude of ARM given in a small steady field is sensitive to finer grain sizes, while $\chi$ is more sensitive to coarser grain sizes. In the sediment core samples of Banerjee et al. (1981) they found that small slopes in the ARM- $\chi$ plot indicate a paucity of fine grains. On the contrary, steep slopes show an increase of finer grains. King et al. (1982) constructed a simple phenomenological model based on magnetite grains with different sizes that were plotted in the $\chi_{\mathrm{ARM}}{ }^{-} \chi$-plot. This model enabled King et al. (1982) to detect changes, not only in grains sizes, but also in the amount of magnetite in natural samples, and is traditionally applied as "King-plot."

Isothermal Remanent Magnetization (IRM) is the magnetization produced by the application of a pulse magnetic field at a constant temperature. The highest IRM value that may be obtained in a rock is defined as the saturation IRM (SIRM or $\mathrm{M}_{\mathrm{rs}}$ ). In nature, lightning may produce a high-intensity IRM, generally of low stability. The IRM (or SIRM) strength of a sample depends on the concentration of ferromagnetic (s.l.) particles. However, a field of $1 \mathrm{~T}$ will not saturate antiferromagnetic minerals like hematite and goethite (Liu et al., 2012).

The median destructive field (MDF) is the value at which half of the peak remanent magnetization is lost. It mostly depends on coercivity, and therefore on the composition of the magnetic grains.

\subsection{S-RATIO AND OTHER RATIOS}

The advantage of calculating ratios of magnetic parameters is that the dependence of these parameters may be eliminated. However, this assumption is only valid if the concentration of magnetic minerals is not too high, which may be influenced by grain interactions (Robinson, 1986).

The S-ratio is the ratio between the SIRM and the backfield IRM produced by applying a pulse field (typically of $0.1 \mathrm{~T}$ or $0.3 \mathrm{~T}$ ) in the opposite direction of the previously applied field used to produce the SIRM: $\mathrm{S}_{-0.1 \mathrm{~T}}=-\mathrm{IRM}_{-0.1 \mathrm{~T}} / \mathrm{SIRM}$ or $\mathrm{S}_{-0.3 \mathrm{~T}}=-\mathrm{IRM}_{-0.3 \mathrm{~T}} / \mathrm{SIRM}$ (Liu et al., 2012). It mostly depends on the composition of the magnetic grains. $\mathrm{S}_{-0.3 \mathrm{~T}}$ is used mostly to estimate the relative amount of low- and high-coercivity minerals, or between ferrimagnetic and (canted) antiferromagnetic minerals (Robinson, 1986). $\mathrm{S}_{-0.1 \mathrm{~T}}$ may provide an estimate of the relative amount of low-coercivity ferromagnetic grains (e.g., multidomain magnetite). Hence, an S-ratio that converges to unity indicates that ferrimagnetic minerals are dominant (Liu et al., 2012); in other words, it discriminates between ferrimagnetic and (canted) antiferromagnetic minerals. 
The hard IRM (HIRM) is defined as (SIRM + $\left.\mathrm{IRM}_{-0.1 \mathrm{~T}}\right) / 2$ or $\left(\mathrm{SIRM}+\mathrm{IRM}_{-0.3 \mathrm{~T}}\right) / 2$. It depends on the concentration of minerals with coercivity higher than the applied backfield.

For weak magnetic mineral concentrations (i.e., in absence of significant magnetic interaction), concentration-dependent rock magnetic parameters vary linearly, at least in first approximation, with the abundance of magnetic particles in a specimen. The ratio of two concentration-dependent rock magnetic parameters can be used to infer trends of variation in the grain size and magnetic domain state in a rock sequence. For example, $\mathrm{ARM} / \mathrm{k}$ is used to estimate the variation in the grain size and magnetic domain state of magnetite particles. The ARM/ $\chi$ ratio is inversely related to the size of magnetite grains.

$\mathrm{SIRM} / \mathrm{k}$ or $\mathrm{SIRM} / \chi$, analogously to ARM/k or $\mathrm{ARM} / \chi$, is used to estimate variation in the grain size of magnetite particles (e.g., Rai, 2013). With respect to ARM/k, SIRM/k is more sensitive to changes in the proportion of large grains $(>10 \mathrm{~mm})$. Both parameters vary inversely with the magnetic grain size; however, SIRM/k varies over a wider range than $\mathrm{ARM} / \mathrm{k}$ (Thompson and Oldfield, 1986). Additionally, SIRM/ $\chi$ has been used as an indicator for SD greigite grains in sedimentary environments (Liu et al., 2012).

SIRM/ARM is also a parameter used to estimate grain-size changes in populations of magnetite grains. SIRM/ARM increases as the magnetite grain size increases. This ratio is, however, less sensitive than ARM/k and SIRM/k. An advantage of SIRM/ARM is that it depends only on remanence and is therefore unaffected by SP grains. The ratio $\chi \mathrm{ARM} / \mathrm{SIRM}$ is a grain-size indicator (Peters and Dekkers, 2003; Rai, 2013), while Zhou et al (2015) identified this ratio as the most powerful parameter in discriminating different pollution sources.

The ratio of saturation remanent magnetization $\left(\mathbf{M}_{\mathrm{rs}}\right)$ to susceptibility, $\mathrm{M}_{\mathrm{rs}} / \chi$ is useful to assess the magnetic mineralogy, e.g., high ratios point to pyrrhotite, intermediate to greigite or maghemite, and low values may indicate Ti-magnetite (Peters and Dekkers, 2003).

\section{Non-magnetic measurements of pollution agents}

In general, magnetic measurements are often accompanied by chemical analyses in order to identify the heavy-metal concentrations in the samples. Several studies use X-ray fluorescence (XRF) spectrometry to determine the total heavy metal content (e.g., Yang et al., 2007; Aguilar Reyes et al., 2011; Wang et al., 2012). A mineralogical characterization can be performed using X-ray powder diffraction (XRD; Bourliva et al., 2017). $\mathrm{X}$-ray energy dispersive spectrometry (EDX) is applied to identify the elemental composition (Yang et al., 2007; Zhang et al., 2012; Bourliva et al., 2017).

Several new techniques based on X-ray photon absorption produced at synchrotron radiation facilities have been applied to investigate magnetic properties at the atomic scale (Liu et al., 2012). Their advantage is that they are independent of the physical state of a sample, as opposed to, for example, XRD analysis. One of these techniques, X-ray absorption spectroscopy, helps investigating the oxidation state, bonding, and arrangement of neighbor atoms. It can further be used as a fingerprint to compare unknown samples to standards. $\mathrm{X}$-ray magnetic circular dichroïsm (XMCD) and scanning transmission X-ray microscopy (STXM) are two more methods to investigate magnetic properties. The total amount of heavy metals in a bulk soil sample, and in the magnetic and non-magnetic fractions, can be determined by Inductively Coupled Plasma Mass Spectrometry (ICP-MS).

An important factor in the estimation of health risks is the bioavailablity, because not $100 \%$ of contaminants are bioavailable, meaning, available for the human body for assimilation (Bourliva et al., 2017). Bourliva et al. (2017) determined the vitro oral bioaccesibility of $\mathrm{Pb}$ and $\mathrm{Zn}$ using the unified bioaccessibility method. This approach simulates leaching of a solid matrix in the human gastro-intestinal tract. Aguilar Reyes et al. (2011) determined the bioavailablity of heavy metals by 
first extracting heavy metals using diethylenetriamine penta-acetate, and subsequently measurements with a spectrometer of atomic absorption.

Scanning electron microscope analyses help identify associations between magnetic minerals such as magnetite and heavy metals (Aguilar Reyes et al., 2013) or the overall size distribution and morphology of particles (Urbat et al., 2004; Jordanova et al., 2008; Lu et al., 2011; Chaparro et al., 2013; Castanheiro et al., 2016; Castañeda Miranda et al., 2016; Bourliva et al., 2017).

In the case of soils, various measurements can be performed in order to characterize the physico-chemical properties of soils. For example, Bourliva et al. (2017) determined the $\mathrm{pH}$ of soils, the soil organic matter by the loss-of-ignition procedure, the soil organic carbon content by non-dispersive infrared method (NDIR), and the carbon exchange capacity, among others.

A valuable method to characterize the iron content is the Mössbauer spectroscopy. This type of measurement allows not only determination of the content of the isotope in the sample but also identification of the chemical compound in which the isotope appears (Kopcewicz and Kopcewicz, 1978; Kopcewicz and Kopcewicz, 2001). Mössbauer spectroscopy at different temperatures is used to estimate the size of the iron-containing particles (Kopcewicz and Kopcewicz, 1978). Muxworthy et al. (2002) combined thermomagnetic measurements with Mössbauer spectroscopy to identify the high-temperature magnetic phase as iron.

\section{Magnetic monitoring of anthropogenic pollution in urban areas}

\subsection{DIREGT MONITORING AND FORECASTING OF ANTHROPOGENIC POLLUTANTS}

Active monitoring of PM with air quality monitoring stations or in air filters allows obtaining localized time series of particle concentrations. Active collection onto air filters allows the differentiation of various size classes (e.g., Lehndorff et al., 2006). For example, Heo et al. (2017) analyzed hourly $\mathrm{PM}_{10}$ mass concentration data for 16 years from Seoul (Korea). This direct measurement allowed them to observe a stagnation of the decline of mass concentration with the final goal to take action to improve air quality. Revuelta et al. (2014) carried out a combined magnetic-chemical study of 15 daily $\mathrm{PM}\left(\mathrm{PM}_{10}, \mathrm{PM}_{2.5}\right.$ and $\left.\mathrm{PM}_{1}\right)$ aerosol samples in Barcelona, Spain. They distinguished crustal sources of North Africa from other sources of $\mathrm{PM}_{1}$.

In order to react to changes in PM levels and to warn the population of unfavorable conditions, policy makers need reliable forecasting models of daily PM concentrations. Stadlober et al. (2012) suggested a multiple linear regression and generalized linear models for the sites of Graz, Austria and Brno, Czech Republic as suitable monitoring tools and as a base for decision makers. Perez and Reyes (2006) applied an integrated artificial neural network model to predict the maxima of the 24 hour average of $\mathrm{PM}_{10}$ in Santiago, Chile. Their model takes into account the spatial pattern of $\mathrm{PM}_{10}$ distribution during the evening of a given day in order to forecast the concentration at the same stations the next day.

Recently, the differential absorption lidar (DIAL) technique has been applied in a mobile system to detect the total flux of certain pollutants such as $\mathrm{SO}_{2}$ and $\mathrm{NO}_{2}$ (Zhao et al., 2017). Of special interest for China is the monitoring of atomic mercury $(\mathrm{Hg})$, which is considered a particularly hazardous heavy-metal pollutant. With the mobile DIAL system, $\mathrm{Hg}$ can be monitored in ranges of typically a few $\mathrm{km}$. As part of the mobile system a remote laser-induced break-down spectroscopy (LIBS) system also allows the detection of the elemental composition in soils.

In the last few years, atmospheric concentrations of $\mathrm{PM}_{10}$ have been measured as well with satellite remote sensing systems. This space-based monitoring, based on Aerosol Optical Depth (AOD) measurements, e.g., from the MODIS sensor onboard the Aqua Satellite, is a quantitative 
measure of the amount of the depletion that a beam of solar radiation undergoes as it passes through the atmosphere. Michaelides et al. (2017) analyzed satellite data with a resolution of $10 \times 10$ $\mathrm{km}$.

\subsection{BIOMAGNETIC MONITORING}

Airborne pollution exposure data obtained from networks of monitoring stations frequently have a low spatial resolution and are therefore not able to capture small-scale variations in PM concentrations and particle size. Monitoring stations are often several kilometers apart, which impedes identifying and quantifying causal links between the degree of exposure to PM and the likelihood of adverse health impacts within a population. Furthermore, conventional monitoring stations are generally located far from residential areas and often situated above $3 \mathrm{~m}$ height (Mitchell et al., 2010). Therefore, biomagnetic monitoring of PM has the potential to provide spatial and temporal high-resolution data of polluted areas (Matzka and Maher, 1999; Mitchell et al., 2010; Hofman et al., 2017). Furthermore, it is more economic and faster than many geochemical methods. The ability to capture fly ash and magnetic particles depends very much on the type of surface, e.g. tree trunk bark is about two orders as effective as certain leaves (Evans and Heller, 2003), while the receptor material needs to be insignificantly magnetic.

\subsubsection{PLANTS, MOSSES, AND LICHENS}

Mitchell et al. (2010) investigated $\mathrm{PM}_{10}$ deposition on birch and lime tree leaves, both on initially "clean" (glasshouse grown) specimens and on roadside trees and found that PM gradually accumulated on the surfaces of deciduous tree leaves until a dynamic equilibrium between particle deposition and particle loss is reached. For birch and lime trees, the time required for equilibrium to be reached is of the order of 6 days. When dynamic equilibrium has been reached, leaf SIRMs can act as a quantitative measure for ambient $\mathrm{PM}_{10}$ concentrations. The main processes involved in reaching dynamic equilibrium are dry deposition and particle re-suspension, both driven by air turbulence.

Some authors found conifers more reliable than broadleaf trees due to higher deposition velocities for fine to ultrafine particles and due to higher capture efficiency (e.g., Beckett et al., 2000). Furthermore, a contrasting relationship has been reported between leaf SIRM and exposure time for waxy evergreen and deciduous leaves. For Pinus nigra, for example, Lehndorff et al. (2006) observed an increase in needle SIRM during the first 20 months, with an equilibrium reached after approximately 26 months of exposure. Such long equilibration times suggest that the leaf SIRM is dominated by incremental incorporation of magnetic particles within the cuticular structure.

Rai et al. (2016) tested Lantana camara as a biomonitor, which is the most dominant weed in Aizwal, Mizoram, India. Samples collected in rural areas have lower values of magnetic susceptibility and remanent magnetization compared to samples from urban areas. Lantana camara proves to be a suitable biomonitor for PM (Rai et al., 2016).

Barima et al. (2014) investigated the potential of leaves from four different herbaceous and tree species as a bioindicator of urban PM pollution. The four species were selected based on their distribution in different land use classes, their convenience to harvest, and the width of their leaves for easy scanning. The species were Amaranthus spinosus, Eleusine indica, Panicum maximum, and Ficus benjamina, all plants that are home to the tropical urban environment of Abidjan, Ivory Coast. Barima et al. (2014) showed that the SIRM is at least four times higher in the vicinity of main roads and industrial areas than in parks and residential areas. Distances of $0-5 \mathrm{~m}$ seem to be most affected by PM pollution. The slightly hairy leaves of Amaranthus spinosus and the waxy leaves of Ficus benjamina had largest SIRM values.

Giordano et al. (2013) found that the accumulation of urban PM from Naples, Italy was highest in moss (Hypnum cupressiforme), followed by lichen 
(Pseudevernia furfuracea), and finally cellulose filters, with the lowest accumulation capacity. They further found that the elemental uptake increased during rainy periods. Especially oven-dried moss preserved a high elemental accumulation capability. Jordanova et al. (2010) performed a detailed study on different vegetation samples (lichens, mosses, poplar leaves, dandelion, and needles) for several highly polluted and clean sites in Bulgaria. They conclude that lichens and mosses have higher accumulation capacities and therefore they can be the best biogenic dust collectors.

\subsubsection{SOIL CONTAMINATION}

Boyko et al. (2004) tested the repeatability of magnetic susceptibility mapping in two field campaigns on 129 sites in North and West Austria on a regular grid of $10 \times 10 \mathrm{~km}$ and on a high-resolution grid of $2 \times 2 \mathrm{~km}$ in the polluted Steyreggerwald near the town of Linz. The measurements obtained with a Bartington Instruments MS2D handle were compared with magnetic susceptibilities of soil reference material taken at the measured sites. The Bartington handle measures susceptibilities in the top 6-8 $\mathrm{cm}$, whereas for the reference material the upper $3.5 \mathrm{~cm}$ of the topsoil were sampled. Boyko et al. (2004) found significant correlation between magnetic susceptibilities from the readings in the field with the ones of the reference material. Especially for the high-resolution grid, the 33 topsoil measurements reveal high correlation $\left(\mathrm{R}^{2}=0.98\right.$; Figure 9). Factors that affect the repeatability of the field measurements are, for example, inhomogeneities within the measured place, positional precision, different equipment sets, plant cover, and anthropogenic activity.

Soils contaminated by mining and processing industry are often recultivated to restore the natural environment (Jordanova et al., 2017). Jordanova et al. (2017) applied magnetic methods to determine the degree of soil restoration close to a metallurgical copper-processing plant in Bulgaria. They found an enhanced amount of magnetite in the uppermost levels of the Technosol, which may have formed through the reduction of hematite that was initially present in the dump material. Magnetic grain size proxies $\left(\mathrm{ARM} / \mathrm{IRM}_{100 \mathrm{mT}}, \chi_{\mathrm{fd} \%}\right)$ identify magnetic grains larger than SP grains, suggesting that the enhanced magnetic signal partly originates from fly ash additions to the soil. Fly ash, commonly in the form of alkaline ash from industrial processes, is often applied in soils for restoration purposes as a liming agent (Jordanova et al., 2017). However, $\chi$ in the uppermost level shows a linear positive trend with the age of the forest stand, indicating that the magnetic enhancement may be linked to pedogenic processes. Furthermore, depth variations of the magnetic parameters along the soil profiles suggest that with time after recultivation, magnetic particles from pedogenic processes and/or from fly ash spread progressively deeper, reaching about $15 \mathrm{~cm}$ in the 25-year-old silver-birch forest.

Li et al. (2017) combined magnetic methods with XRF and other non-magnetic methods to investigate the fate of heavy metals in different types of soil horizons. The heavy-metal contents may differ in particular soil horizons because soils are governed by their proper physicochemical properties such as $\mathrm{pH}$, soil moisture, and amount of organic matter and clay minerals. They found a clear difference between the red clay horizon and the upper and lower yellow silt horizons; the $\chi_{\text {If }}$ signal was stronger in the clay horizon due to a higher amount of ferromagnetic (s.l.) minerals in the iron-bearing clays and mafic silicates,

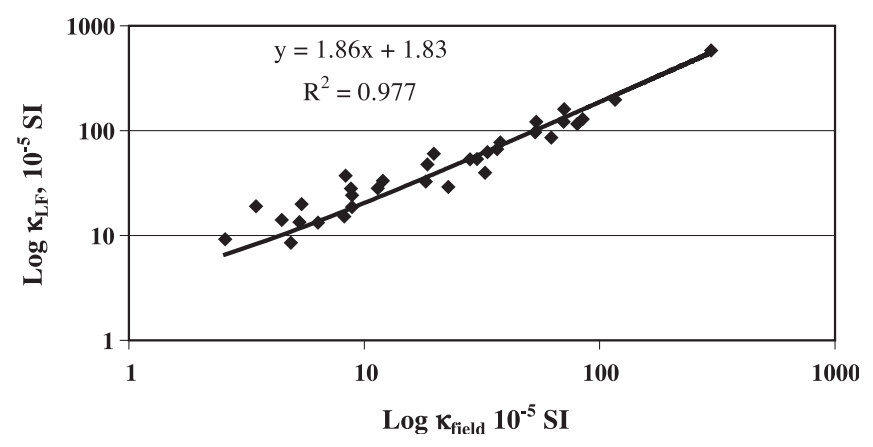

Figure 9 Results of the high-resolution screening of Linz area. Ratio of volume magnetic susceptibility of the soil reference material versus susceptibility measured in field (Boyko et al. 2004). 
consistent with higher weathering and pedogenic processes compared to the silt layers ( $\mathrm{Li}$ et al., 2017). The clay layer also showed values of $\chi_{\mathrm{fd} \%}$ $>6 \%$, that were higher than those in the silt layer, indicating larger amounts of SP grains. The trend in the clay layer with higher magnetic susceptibility values correlates with mean concentrations of heavy metals 1.5 times higher than in the silicate layer.

\subsubsection{STREET DUST}

Cortés et al. (2015) calculated color indices for dust collected on urban streets. They used the RGB system and grouped each color using the Munsell tables (Munsell Color, 2000). Results were compared to XRF measurements to identify the elements contained in the dust samples. The study showed that $\mathrm{Rb}$ and $\mathrm{V}$ are present in largest concentrations in dark red dusts, while $\mathrm{Ni}$, $\mathrm{Cu}, \mathrm{Zn}$, and $\mathrm{Pb}$ are mainly present in gray dusts. In general, ash produces gray colors, whereas red and brown colors often stem from local soils. However, for each city or sampling area, colors should be determined beforehand in a reference study (Cortés et al., 2015). Xie et al. (2000) investigated the organic matter content, e.g., PAH, of street dust in Liverpool, UK. Their main goal was to determine if magnetic measurements correlate with organic matter content. In order to quantify the organic matter content, weighed samples of dust were oven dried at $105^{\circ} \mathrm{C}$ overnight, reweighed and then ignited in a muffle-furnace. The loss-on-ignition method is a common technique to estimate organic matter content in soil samples. Ignition at $375^{\circ} \mathrm{C}$ for 16 hours worked best to remove organic matter without structural water loss from inorganic components. The loss of inorganic carbon compounds is reported to start at temperatures $>400^{\circ} \mathrm{C}$ (e.g., Xie et al., 2000). The amount of organic compounds was determined to be $4 \pm 1.3 \%$. Magnetic measurements indicate that the main magnetic grain sizes are $\mathrm{MD}$ grains, with smaller amounts of SP and SD grains. Furthermore, Xie et al. (2000) found the strongest correlation between organic matter content and
$\chi_{\mathrm{fd}}(\mathrm{R}=0.607)$, suggesting that magnetic methods can be useful proxy methods for organic matter in street dust.

\subsubsection{CONTAMINATION OF URBAN RIVERS, HARBORS, LAKES, AND SEAS}

Zhang et al. (2011) focused on the discrimination between contributions of different pollution sources in urban river sediments from Loudi City, Hunan Province, China. Furthermore, they aimed to establish a relationship between magnetic parameters and heavy metal contamination, obtained from chemical, microscopic, and statistical methods. The magnetic investigation revealed that PSD and MD magnetite occur as dominant ferromagnetic phases, with small amounts of SP particles. The SP magnetite particles likely came from pedogenic processes in the subtropical region. Some heavy metals found in the sediment (Be, Cs, $\mathrm{Rb}, \mathrm{Nd}, \mathrm{Co}, \mathrm{Ni}, \mathrm{Ba}$ ) do not correlate with the magnetic parameters. Their main sources were probably pedogenic processes in the catchment region upstream. On the contrary, Fe, V, Cr, Mo, Zn, Pb, $\mathrm{Cd}$, and $\mathrm{Cu}$ showed a significant correlation with $\mathrm{M}_{\mathrm{s}}, \chi, \chi_{\mathrm{ARM}}$, and, especially, with SIRM, suggesting that these metals and their related magnetic particles stem from anthropogenic sources from the urban zone. Furthermore, SIRM does not include the contribution of pedogenic SP particles, making it the optimum proxy parameter for the detection of heavy metals in river sediments. Knab et al. (2006) investigated the influence of complex geological settings, with magnetically strong rock formations, on the magnetic signal of river sediments from the river Moldau, Czech Republic. They used magnetic susceptibility, which has been shown to reflect industrial input into river sediment, to distinguish between anthropogenic and natural contribution in river sediments (Knab et al., 2006). By comparing susceptibility measurements from outcropping rocks, soils close by the river, and river sediments, they found that the geological background value should be considered locally as a magnetic source of primary significance. Nevertheless, the anthropogenic 
contribution could be clearly observed in areas of minor lithogenic contribution (Knab et al., 2006). In another approach, Frančišković-Bilinski et al. (2014) measured $\chi$ and IRM from predominantly unpolluted rivers from Croatian and Slovenian flysch areas and compared the results to several rivers and a lake from the Celje old metallurgic industrial area (Slovenia). Sediments from the unpolluted flysch rivers had extremely low $\chi$ and IRM values, with mass susceptibility between 0.6 and $5.1 \times 10^{-7} \mathrm{~m}^{3} / \mathrm{kg}$ and IRM between 0.7 and $7.9 \mathrm{~A} / \mathrm{m}$. On the contrary, in the industrial area $\chi$ and IRM were much higher with $\chi$ between 1.3 and $38.3 \times 10^{-7} \mathrm{~m}^{3} / \mathrm{kg}$ and IRM between 0.9 to $100.4 \mathrm{~A} / \mathrm{m}$. The highest $\chi$ values were found in an area where significant amounts of heavy metals were reported in earlier studies. Sediments of the industrial area have mostly diamagnetic quartz as a major lithogenic mineral, with small amounts of carbonate, while in sediments of the flysch (karstic) rivers, carbonate minerals dominate.

\subsection{METEOROLOGICAL, GLIMATIC, TEMPORAL, AND SOURGE-RELATED EFFEGTS}

Concentrations of magnetic particles are governed by exposure time, source distance, source strength, and sampling height, as well as number and intensity of rainfall events, and wind velocity and direction (e.g., Hofman et al., 2017). Rainfall events lower both ambient $\mathrm{PM}_{10}$ concentrations and magnetic parameters of leaves, but contrasts have also been reported for different plant species (Mitchell et al., 2010). For deciduous leaves, Mitchell et al. (2010) reported a decrease in magnetic strength of leaves due to rainfall effects and suggested that rain-induced wash-off of magnetic particles from tree leaves is likely to vary according to species and leaf characteristics, in addition to rain intensity, canopy position, and degree of shelter. For pine needles, Urbat et al. (2004) demonstrated that rainfall removes only a small portion of the captured $\mathrm{PM}$, as particles are trapped in the surface wax layer and stomatal pores. For another evergreen species, Quercus ilex, Szönyi et al. (2008) reported no clear indication that rain systematically decreased the intensity of leaf magnetic properties. However, Zhang et al. (2006) observed that the magnetization for pine trees (Pinus pumila) was lower at a later sampling event compared to an earlier sampling event, which they explained by a heavy rain event prior to the later sampling. At least half of the magnetic susceptibility signal was removed by the heavy rain. However, the magnetic signal was still significant and had a sample-distance dependence, suggesting that rain cannot completely remove the accumulated PM. Kardel et al. (2011) showed a limited effect of rain-induced wash-off and a strong correlation with accumulated $\mathrm{PM}_{10}$ during the growing season, suggesting some time-dependent incorporation of magnetic particulates in the epicuticular wax layer. Xu et al. 2017 developed artificial rainfall experiments in order to investigate the effects of rainfall on PM wash-off mass. They used four broadleaf species, one of which was evergreen and the other deciduous. Not only rainfall duration but also intensity has an effect on PM wash-off. In addition, an exponential decay was observed between cumulative wash-off rates and rain amount.

Besides meteorological factors, climatic factors that act on larger time and spatial scales also affect the accumulation of pollutants on surfaces (Rodríguez-Germade et al., 2014). By comparing data from cities with different climatic regimes, e.g., subtropical monsoon, continental, oceanic and Mediterranean climates, Rodríguez-Germade et al. (2014) found that atmospheric humidity plays an important role in the accumulation of particles on leaves. Less humid climates, as well as low soil water availability, causes the leaves' stomata to open, which increases the water loss by transpiration (Barceló et al., 2001; Rodríguez-Germade et al., 2014;). These effects enhance the leaves' capacity to incorporate particles in their surface tissue. Besides the incorporation of particles, the lithic component of urban dust of the accumulated particles depends on atmospheric humidity. Rodríguez-Germade et al. (2014) noticed that the lithic component is stronger in arid regions where the relative humidity is low. Furthermore, 
they compared the correlation between different metal concentrations and magnetic susceptibility, and found lower correlation in cities with lower moisture.

In general, concentration of PM decreases as wind speed increases, although sometimes an increase in concentration was observed at highest wind speeds (Jones et al., 2010). A small portion of coarse PM was a result of wind-induced resuspension at higher wind speeds. Jones et al. (2010) found a relationship between the mean concentration $(\mathrm{X})$ and the wind speed $(\mathrm{U})$ for different metrics of $\mathrm{PM}$ and NOx, as laid out in the equation

$$
\left.\mathrm{X}=\left\{(\mathrm{U}+\mathrm{c}) \cdot \exp \left(-\mathrm{c}^{\prime} \mathrm{U}\right)\right\}\left\{\mathrm{a}_{1} \mathrm{U}^{0}+\mathrm{a}_{2} \mathrm{U}^{-1}+\mathrm{a}_{3} \mathrm{U}^{3 \cdot 4}\right)\right\}
$$

where $\mathrm{a}_{1}, \mathrm{a}_{2}, \mathrm{a}_{3}$ are constants associated with emission of material from large-area sources, discrete local sources, and marine sources, and which can be determined for each metric and location; $c$ and $c^{\prime}$ are constants that were chosen by iteration. For particulate nitrate, the reduction of concentration happens much faster, and the equation needs to be adapted.

Several studies have dealt with distance to source distribution of PM. For example, Maher et al. (2008) investigated tree leaves from roadside trees and found higher and strongly correlated lead, iron, and remanence values closer to roads. Values and correlations were also higher on road-proximal than road-distal leaves. Higher amounts of pollutants were found on tree leaves next to uphill than to downhill road lanes. Concerning the vertical distribution, Maher et al. (2008) found highest pollution with lead and iron at about $0.3 \mathrm{~m}$ and at 1.5-2 $\mathrm{m}$ height. Considering that common monitoring station collectors are placed at heights of $3 \mathrm{~m}$, it can be supposed that they underestimate pollution concentrations.

\subsection{ANTHROPOGENIC VERSUS NATURAL POLLUTANTS}

In order to distinguish anthropogenic pollution from natural sources in terms of magnetic minerals, heavy metals, or organic compounds present in soils and dusts, several approaches have been suggested. To assess the contamination levels of heavy metals in soils, Müller (1986) introduced the geoaccumulation index, $\mathrm{I}_{\text {geo }}$, in which the current and pre-industrial concentrations of elements are compared.

$$
\mathrm{I}_{\text {geo }}=\log 2\left(\mathrm{C}_{\mathrm{n}} / 1.5 \mathrm{~B}_{\mathrm{n}}\right)
$$

where $\mathrm{C}_{\mathrm{n}}$ is the current concentration of elements in the environment, and $\mathrm{B}_{\mathrm{n}}$ is the geochemical background value in soil. Müller (1969) divided the $\mathrm{I}_{\text {geo }}$ values in a scale ranging from $\mathrm{I}_{\text {geo }} \leq 0$ (uncontaminated) to $I_{\text {geo }} \geq 5$ (extremely contaminated).

The "enrichment factor," the ratio of element concentration relative to crustal values, is used to distinguish between natural and anthropogenic contributions to heavy metal contamination in fly ashes. The highest enrichment factor was reported for $\mathrm{Cd}$ with a value of 2400 , while $\mathrm{Pb}$ is in general lower with a value of 740 (Wadge et al., 1986). These authors also found an inverse relation between particle size and the enrichment factor. Another factor to quantify pollution is the contamination factor, CF (Hakanson, 1980). It is the ratio between a single heavy-metal concentration and its background or preindustrial value. $\mathrm{CF}<$ 1 indicates low contamination; $1 \leq \mathrm{CF}<3$ is a moderate contamination; $3 \leq \mathrm{CF}<6$ is considerable contamination; and $\mathrm{CF} \geq 6$ is very high contamination.

The pollution load index (PLI) of Tomlinson $e t$ al. (1980) is

$$
\left.\mathrm{PLI}={ }^{\mathrm{n}} \sqrt{\mathrm{CF}_{1}} \times \mathrm{CF}_{2} \times \cdots \times \mathrm{CF}_{\mathrm{n}}\right)
$$

where $\mathrm{CF}_{\mathrm{n}}$ is the contamination factor for the concentration of each heavy metal. The PLI can be used to compare pollution within different sites.

Spassov et al. (2004) developed a method for distinguishing and quantifying anthropogenic from natural pollution based on demagnetization curves of anhysteretic remanent magnetization (ARM). They calculated coercivity distributions from the demagnetization curves of ARM and 
modelled the components using a linear combination of specific functions. These functions represent the contributions of different sources of magnetic minerals. As a result, they suggested that the $\mathrm{PM}_{10}$ magnetic carriers can be divided in a high-coercivity component originating from exhaust emissions and a low-coercivity component that is derived from natural dust and traffic related pollution.

Magiera et al. (2006) investigated indications to discriminate between lithogenic and anthropogenic influences on magnetic susceptibility $(X)$ in top soils. From horizontal and vertical distributions of $\chi$ measured in topsoil cores, they found, among others, the following indicators of anthropogenic contributions: (1) susceptibility anomalies were observed close to industrial or urban sources of pollution, (2) the strongest enhancement of $\chi$ was found within the uppermost $8 \mathrm{~cm}$, and (3) the enhancement of $\chi$ is accompanied by increased heavy metal content. On the contrary, they suggest the following indicators for a lithogenic origin of enhanced topsoil: (1) the anomalies are found in areas far from industrial or urban centers, (2) the enhancement of $\chi$ increases gradually with depth, and (3) heavy-metal content is generally low and not correlated to $\chi$. The last point is related to the fact that the bedrock determines a large part of the soil type and its properties.

\subsection{DISTINGTION BETWEEN DIFFERENT (ANTHROPOGENIC) SOURGES OF POLLUTION}

Shu et al. (2001) showed that the combined magnetic and geochemical analysis in urban and industrial environments can jointly support the classification of different sources. Dust samples were collected at eleven locations across Shanghai, China. Magnetic susceptibility at low frequencies $\left(\chi_{\mathrm{If}}\right)$ and saturation isothermal remanent magnetization (SIRM) values are largest at sites with highest concentrations of $\mathrm{Fe}, \mathrm{Mn}, \mathrm{Ni}, \mathrm{V}$, and $\mathrm{Zn}$. This correlation confirms that ferrous particles and magnetic spherules in emissions from heavy industry and coal-fired power plants are the main causes of high ferrimagnetic concentrations. Furthermore, magnetic measurements indicate that magnetite MD and PSD grains are largely produced in fossil-fuel combustions.

Zhang et al. (2012) determined the major sources of anthropogenic pollution in the city of Loudi, China through the spatial distribution of magnetic parameters such as magnetic susceptibility. They found that magnetic minerals that incorporate heavy metals mainly stem from an Fe-smelting plant, followed by traffic as the second largest source. Particles are distributed following the main wind direction.

Bivariate plots, or biplots, combining different magnetic parameters can be a powerful tool to discriminate between different anthropogenic sources. Lecoanet et al. (2003) examined which combination of magnetic parameters is most suitable to characterize soil samples. They found a good correlation between SIRM and $\chi$ with $\mathrm{R}^{2}=$ 0.83. Interestingly, the lowest SIRM and $\chi$ values were measured in roadside soil samples, and not in the natural soil background sites. Lecoanet et al. (2003) explain this observation on the one hand with a high paramagnetic content in the road side samples and, on the other hand with post-depositional weathering and/or formation of magnetic phases by pedogenic processes in the natural soil samples (Lecoanet et al., 2003). Also, Zhou et al. (2015) showed that bivariate plots of different magnetic parameters are efficient to discriminate between different sources of contamination. They found a strong correlation between $\chi_{\mathrm{ARM}} / \mathrm{SIRM}$ and $\chi_{\text {ARM }} / \chi$ with clearly separated patches of soils from near a cement plant, near a coal plant, and from the roadside. Furthermore, the ratio $\chi_{\mathrm{ARM}}$ ' SIRM is sensitive to different grain sizes as well as to high- or low-coercivity minerals, e.g., hematite and magnetite/maghemite, respectively (Zhou et al., 2015). By making use of this ratio, Zhou et al. (2015) identified predominantly ferrimagnetic minerals (magnetite or maghemite) in soil samples from roadsides and near the power plant, and hematite from samples near the cement plant. 
6.6. CORRELATIONS BETWEEN HEAVY METALS, MAGNETIC PARAMETERS, HEALTH-RELATED FACTORS, AND ORGANIC MATTER

Wang et al. (2012) investigated the magnetic properties and elemental concentrations of street-dust samples from four different districts. The highest concentrations of magnetic minerals, derived from the concentration depend parameters $\chi_{\text {If }}$, SIRM, "soft" IRM, HIRM and $\chi_{\mathrm{ARM}}$, and heavy metals were found in the two industrial districts. A generally highly significant positive correlation between magnetic concentrations and those of $\mathrm{As}, \mathrm{Cu}, \mathrm{Mn}, \mathrm{Ni}, \mathrm{Pb}$, and $\mathrm{Zn}$ corroborate that a large part of the heavy metals within the four districts is linked to particulate emissions from combustion processes. Through the combination of magnetic and element concentrations, distinct sources of heavy metals could be identified in the two industrial districts. The differences were on the one hand contrasting ferrimagnetic grain sizes, observed in the $\chi_{\mathrm{fd} \%}$-SIRM plot, and, on the other hand, different ferrimagnetic-antiferromagnetic fractions, detected in the $\mathrm{S}_{-300}{ }^{-} \chi_{\text {If }}$ plot.

Xie et al. (2000) investigated the organic content in street dust in Liverpool (UK) and found that it had the strongest correlation with $\chi_{\mathrm{fd}}(\mathrm{R}=$ 0.607). Therefore, the authors suggested that certain magnetic measurements may be suitable as proxies for organic content matter in street dust. However, Shilton et al. (2005) argued that data should be separated into site-specific correlations. They took street dust samples from three different roads with very different traffic patterns. When comparing the correlations $\chi_{\mathrm{fd} \%}$ and $\chi_{\mathrm{ARM}} / \mathrm{SIRM}$ with the organic content for the three roads, differences were obvious. While $\chi_{\mathrm{fd} \%}$ seemed to be more consistent within all three roads, $\chi_{\mathrm{ARM}}$ ' SIRM exhibits completely different trends. Therefore, Shilton et al. (2005) concluded that there are significant correlations between organic matter in urban street dust and magnetic parameters, but the correlations can be very different, even within the same area.

Magnetic susceptibility of respirable pollutant particles has been shown to have a strong correlation to heavy metals such as $\mathrm{Pb}, \mathrm{Zn}, \mathrm{Cd}$, and As and, furthermore, to their mutagenic potency, i.e., their ability to cause mutations in the genome (Morris et al., 1995; Ďurža, 1999; Petrovský et al., 2001; Shu et al., 2001; Morales et al. 2016). Morris et al. (1995) first indicated that there is a direct association between magnetic susceptibility and mutagenic potency of inhalable PM (content of PAH). They investigated 62 air filter extracts and found a high correlation between mutagenicity and magnetic susceptibility (Figure 10). The linear regression shows a correlation factor of $\mathrm{R}=0.80$. This indicates that $\chi$ may be used as an indicator for mutagenetic activity of respirable PM.

\section{Discussion and critique}

\subsection{INTERNATIONALLY ACGEPTED THRESHOLD VALUES FOR POLLUTANT AGENTS}

Research efforts have not yet found evidence for a safe level of PM exposure, below which negative effects for health do not occur. However, in the air quality guidelines (AQG) from WHO (2006) a

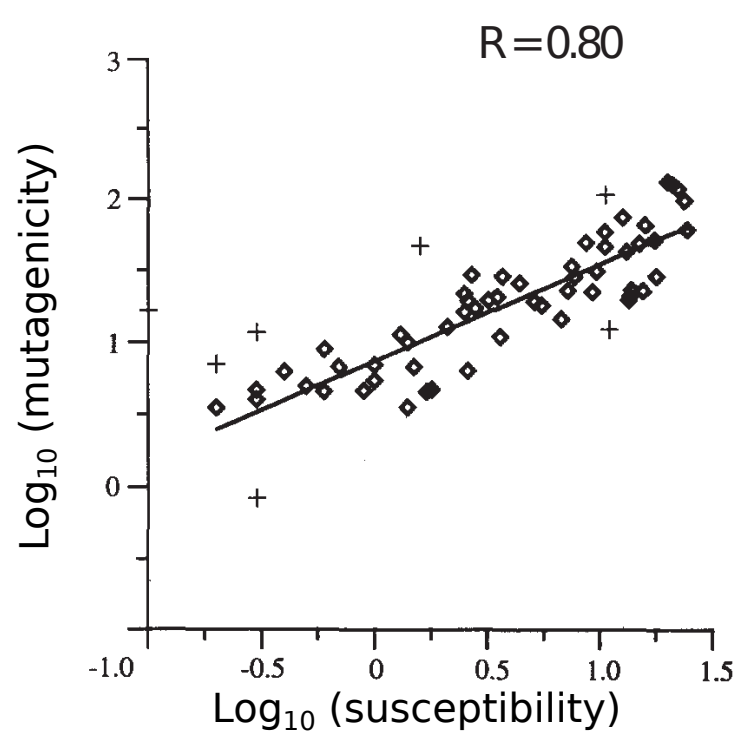

Figure 10 Mutagenicity (expressed as revertants, which is a mutant gene, individual, or strain that regains a former capability by undergoing further mutation per $\mathrm{m}^{3}$ of air) of polycyclic aromatic compounds and magnetic susceptibility $\left(10^{-6} \mathrm{cgs}\right.$ per $\mathrm{m}^{3}$ of air) (Modified after Morris et al., 1995). 
maximum level of $\mathrm{PM}_{10}$ of $20 \mu \mathrm{g} / \mathrm{cm}^{3}$ as an annual mean was suggested. In 2010 only 9 of 34 member states were below this level. Recent estimates for $\mathrm{PM}_{2.5}$ were published as part of the Global Burden of Disease, Injuries, and Risk Factors Project. The threshold values of the AQG for $\mathrm{PM}_{2.5}$ are $10 \mu \mathrm{g} /$ $\mathrm{m}^{3}$ for an annual average and $25 \mu \mathrm{g} / \mathrm{m}^{3}$ for 24 hours, and for $\mathrm{PM}_{10}$ it is $20 \mu \mathrm{g} / \mathrm{m} 3$ for an annual average and $50 \mu \mathrm{g} / \mathrm{m}^{3}$ for 24 hours. Nevertheless, air pollution may be higher in areas with power plants, heavy traffic, and other sources. Different measures are required to be applied to protect the population in these areas (WHO, 2006). The critical period of exposure is most probably one year, e.g., exposure to $\mathrm{PM}_{2.5}$ reduces life expectancy by about 8.6 months on average. Health improvements can be expected to start almost immediately after reduction of air pollution (WHO, 2013).

It has to be noted that the AQG are recommendations and not binding standards. Air quality standards are meant to be defined by each country to protect their population, according to the WHO. These standards may vary according to the solutions applied for reducing air pollution based economic, political, and social factors, among others. Therefore, the WHO explicitly acknowledges that governments adopt their own standards depending on their country-specific circumstances (WHO, 2006). However, this non-binding AQG may avoid commitment of certain countries to reduce contamination. At least, a common upper level of contamination should be binding for all countries, such as one of the interim targets suggested by the WHO (WHO, 2006). These interim targets serve as milestones in reaching the AQG. Finally, ultrafine particles show high evidence of potential negative effects on health, but are not included in the AQG. There is still a lack of studies to be able to define common standards for these particles.

In the last few decades, the number of megacities - urban agglomerations with a population larger than 10 million people - have been growing (Baklanov et al., 2016). Most of the megacities are located in developing countries that do not have the necessary financial resources, air quality management plans, or political stability to counter heavy air pollution (Baklanov et al., 2016). Air pollution problems in megacities are influenced by topography, demography, meteorology, mobility and transportation patterns, fuel quality and usage, level and rate of industrialization, and socioeconomic development (Baklanov et al., 2016). Therefore, air quality standards need to consider the specific factors that produce and influence air pollution. Air pollution mitigation strategies should include the use of clean technologies and policy measures (Baklanov et al., 2016). However, there are still large socioeconomic and political barriers to the transition to new eco-friendly technologies (Baklanov et al., 2016).

Soil pollution by heavy metals has been a worldwide concern, and countries have developed laws and regulations to control them, e.g, the US, Mexico, Nigeria (US EPA, 1996; SEMARNAT, 2007; Wuana and Okieimen, 2011, respectively). However, there is no consensus on the permissible heavy metal concentrations, and much less on the amount of heavy metals per type surface. One of the most commonly used methods to determine the concentration of heavy metals in soil is the total element analysis (USEPA method 3050, Wuana and Okieimen, 2011). In general, the level of heavy-metal contamination is expressed as mg metal $/ \mathrm{kg}$ soil. However, the total element analysis does not take into account moisture content, and may therefore alter the concentration by including soil water (Wuana \& Okieimen, 2011).

\subsection{DISGRIMINATION BETWEEN NATURAL AND ANTHROPOGENIG POLLUTION}

The magnetic trace is composed of a natural and an anthropogenic contribution. Therefore, one of the main challenges is to discriminate between the two signals. Areas that are most magnetic are not necessarily the most contaminated - the amount of ferromagnetic (s.l.) minerals depends on lithological and pedological characteristics of the soil. A straightforward way to identify anthropogenic pollution is by comparing top- and subsoil samples 
(Hanesch et al., 2007). Contaminants accumulate, in general, in the uppermost centimeters of the soil $(0-20 \mathrm{~cm})$. Therefore, a higher magnetic value in the uppermost layer with respect to the subsoil indicates contamination. More specifically, a negative difference between the magnetic parameter of top- and subsoil is attributed to a highly magnetic bedrock (e.g., ore bodies), while a high positive difference is considered an anthropogenic anomaly (Hanesch and Scholger, 2002).

Additionally, statistical methods, such as the median absolute deviation methods, the boxplot method, the population modeling method, and the quantification of anomalous values by the Geoaccumulation Index identify anomalies of magnetic values that may be attributed to contamination (Hanesch et al., 2007). It is of major importance to bear in mind background values, because high magnetic values can wrongly be attributed to anthropogenic sources. Hanesch et al. (2007) reported extremely high magnetic susceptibility values for soil samples in the Alps of Austria that could solely be attributed to the geological parent material. Therefore, a precise knowledge of the geology and soil types of the investigated area, or any other method to include background values is important for the correct interpretation of magnetic enhancement of a specific area. Jordanova et al. (2008) investigated soil samples in the close vicinity of chemical-industry-related areas and cement and power plants. Pollutants from these sources do not contain as much magnetic minerals as pollutants from the metallurgical industries, mining, or coal-burning power plants. To account for the relatively low signal, Jordanova et al. (2008) corrected the data for the effect of different soil types. Another method to includs background values is to compare magnetic parameters of the samples of interest with those from a sample from a suburban area with little human influence, or a conservation area (e.g., Sánchez-Duque et al., 2015).

Apart from the question of background values, there are no common standards defined by the environmental magnetism community. The variety of methods does not allow a direct comparison between magnetic enhancement in different areas. Therefore, the need for standard methods for determining background values has grown. Furthermore, the background signal is usually locally defined and has to be determined for each specific area. Additionally, it may change with time, since the use of soil may vary.

There are few studies in which thresholds of magnetic parameters for soils are defined. For example, Cejudo-Ruíz et al. (2015) defined a threshold value of IRM above which the magnetic enhancement can be attributed to anthropogenic pollution. Using these threshold values, the authors identified contaminated soils in Mexico City. It is necessary that in each locality these thresholds are defined separately. Again, the types of soil and lithology have to be taken into account. Nevertheless, defining threshold values for magnetic parameters is a necessary step in the determination of anthropogenic pollution. Threshold values for certain magnetic parameters, however, are not equally well correlated with each heavy metal.

\subsection{GORRELATIONS BETWEEN MAGNETIC PARAMETERS AND HEAVY METALS}

The correlation between magnetic properties and heavy metals can help distinguish different sources of pollutants. In each case, it should be assessed which magnetic parameter is more appropriate than others. The choice of parameter depends on the type of contamination as well as the type of magnetic biomonitoring. In the majority of the studies, concentration-dependent magnetic parameters are compared to geochemically determined concentrations of heavy metals.

Low-field magnetic susceptibility is the most commonly used magnetic parameter due to its fast acquisition and successful application as qualitative proxy for pollution agents in a large number of studies (e.g., Hoffmann et al., 1999; Hanesch and Scholger, 2002; Boyko et al., 2004; Magiera et al., 2006; Hanesch et al., 2007; Kanu et al., 2014). It is assumed that increased $\chi$ values correlate with increased amounts of heavy metals due to their 
common anthropogenic origin. Magnetic remanences such as ARM and IRM are frequently used indicators of the concentration of remanence carrying minerals (Jordanova et al., 2017). And grain size- or coercivity-dependent parameters such as $\chi_{\mathrm{fd} \%}, \mathrm{k}_{\mathrm{ARM}} / \mathrm{k}$, and S-ratio are popular parameters in biomagnetic monitoring studies. However, a relationship between these magnetic parameters and heavy metal concentrations has not equally been found for all heavy metals. The amount of ferromagnetic (s.l.) minerals not only depends on the anthropogenic pollution, but also on, for example, natural sources of magnetic minerals, different background values in soils depending on soil type or different lithology influences, and different types of pollution sources. For example, Chaparro et al. (2006) compared several magnetic parameters to chemically determined concentrations of heavy metals and found that $\mathrm{k}_{\mathrm{ARM}} / \mathrm{k}$, S-ratio, and $\mathrm{H}_{\text {cr }}$ correlate better with concentrations of $\mathrm{Pb}, \mathrm{Cu}, \mathrm{Zn}, \mathrm{Cr}$, and Fe than $\chi, \mathrm{ARM}$, and SIRM. This and many other examples show that correlations between heavy metals and magnetic parameters need to be classified and thoroughly selected in order to apply them in repeated temporal and spatial monitoring campaigns.

\subsection{AMBIGUITIES OF MAGNETIC PARAMETERS AND MEASUREMENTS}

For materials with low concentrations of ferromagnetic (s.l.) minerals, the sensitivity of some susceptibility meters may be too low to obtain a reliable measurement (Wang et al., 2010). The same is true for remanent magnetization. Sagnotti et al. (2006) reported that the magnetic susceptibility of air filters was not measurable with a KLY-3S kappabridge, which has a sensitivity of 3 $\times 10^{-8}$ SI. Therefore, they averaged five repeated measurements of each filter to obtain a reliable result. Boyko et al. (2004) measured the magnetic susceptibility of soil samples using a Bartington Instrument MS2B sensor. For cross-calibration, 100 randomly selected samples were measured using a KLY-2.0 kappabridge and yielded a strong positive correlation $\left(\mathrm{R}^{2}=0.96\right)$.
The frequency dependent $\mathrm{k}_{\mathrm{fd}}$ is a complex parameter affected by both grain size and grain concentrations within the SP grain-size range. Therefore, a quantitative interpretation of $\mathrm{k}_{\mathrm{fd}}$ is difficult (Dearing et al., 1996). Natural samples like soil contain, in general, a distribution of grain sizes ranging from very small SP to large MD. Hence, a specific data point in the Day plot does not necessarily represent the grain sizes of the measured sample, but can also be a mixture of various grain sizes. Furthermore, natural samples can also contain a mixture of different magnetic minerals, hampering an interpretation of the Day plot.

\section{Future of magnetic studies on anthropogenic pollution}

In order to identify pathways and sources of air pollution, statistical methods such as trajectory clustering have been used (e.g., Ashbaugh, 1983; Sirois and Bottenheim, 1995; Borge et al., 2007). Qiao et al. (2017) applied a statistical clustering technique to a 5-month dataset of atmospheric trajectories to identify the particulate matter sources and long-range transport patterns that can influence air pollution in Beijing, China during the 2008 Olympic games. Before and during the Olympic games a series of measures were implemented; for example, the relocation of industrial plants with large emissions outside of the city or the introduction of new standards to reduce vehicular emission and use. Several 3-day back-trajectories $500 \mathrm{~m}$ above ground level arriving at Beijing were calculated, which identified five clusters outside of Beijing (Qiao et al., 2017). These kinds of methods, together with biomonitoring campaigns along the trajectories, have great potential to identify sources of heavy contamination and their pathways.

Aerosol particles affect the hydrological cycle to a large scale because they act as cloud condensation and ice nuclei. Furthermore, they affect the cloud albedo and concentration of water droplets in the clouds (Cao, 2017). Therefore, 
new engineering measures have been attempted to capture particles on a variety of scales. Cao (2017) summarized methods to trap particles on the nano- to microscale, with diameters of 100$1000 \mathrm{~nm}$, that are developed for air purification industries for clean rooms and for the removal of pollutants from ambient air. Furthermore, Liu et al. (2015) proposed a new filtration material that exhibits $\sim 95 \%$ efficiency in removal of $\mathrm{PM}_{2.5}$. On a regional-synoptic scale Pui et al. (2014) proposed a "great wall" of solar panels to mitigate yellow dust storms in China. The solar panels generate electricity, while the wall serves as wind break and to capture airborne dust during wind storms.

An economic measure to remove pollutants from the atmosphere is to use plants. Several studies tested plants in terms of their abilities to capture PM. Cardoso-Gustavson et al. (2016) investigated Tillandsia usneoides, aerial epiphytic bromeliads, close to a highway in São Paulo State, Brazil. This type of plant absorbs water and nutrients directly from the atmosphere. Adsorption of heavy metals predominates in the scales that are a type of non-secretory trichomes. Hofman et al. (2017) suggested a number of important aspects that need further investigation; for example, the identification of (1) the most suitable leaf anatomy and morphology to capture PM (e.g., size, trichomes, surface roughness), (2) the preferred leaf physiology (e.g., wax characteristics, encapsulation of PMs and wax regeneration), (3) PM properties that support accumulation and entrapment processes, and (4) the influence of meteorological conditions (e.g, rain, wind, drought). Depending on the climate, the most suitable plants, mosses, or lichens need to be identified in order to perform continuous biomonitoring on a larger scale.

Future studies need to combine pollution data from satellites, stations, and magnetic measurements to obtain a highly resolved net of pollution information. With the integration of chemical-meteorological models, sources and pathways of atmospheric pollution can be identified.

\section{Conclusions}

(Bio)magnetic monitoring of pollution from the atmosphere, on leaves, in soils, in sediments, and in urban dust is a constantly growing area of research, as demonstrated by an increasing number of publications in the last few years. Magnetic methods have proven to be economic alternatives to costly chemical analyzes. Furthermore, ferromagnetic minerals are useful proxies for heavy metals, although some heavy metals correlate better than others. However, after a study of background values, type of sampling matrix, and favored correlations, monitoring campaigns using magnetic parameters will be of great use. Spatial and temporal monitoring results serve as a basis for policy makers to take appropriate actions in case of heavy pollution events, and to protect the population and the ecosystem.

\section{Acknowledgements}

This work was supported by the Secretaría de Ciencia, Tecnología e Innovación de la Ciudad de México [SECITI/051/2016]. We like to thank William Lowry for his useful input.

\section{References}

Aguilar Reyes, B., Bautista, F., Goguitchaichvili, A., Morton, O., 2011, Magnetic monitoring of top soils of Merida (Southern Mexico): Studia Geophysica et Geodaetica, 55(2), 377-388. https://doi.org/10.1007/ s11200-011-0021-6

Aguilar Reyes, B., Cejudo Ruiz, R., MartínezCruz, J., Bautista, F., Goguitchaichvili, A., Carvallo, G., Morales, J., 2012, Ficus benjamina leaves as indicator of atmospheric pollution: A reconaissance study: Studia Geophysica et Geodaetica, 56(3), 879-887. https://doi. org/10.1007/s11200-011-0265-1 
Aguilar Reyes, B., Bautista, F., Goguitchaichvili, A., Morales Contreras,J.J., Owen, P.Q., Carvallo, C., Battu, J., 2013, Rock-magnetic properties of topsoils and urban dust from Morelia (>800000 inhabitants), Mexico: Implications for anthropogenic pollution monitoring in Mexico's medium size cities: Geofisica Internacional, 52(2), 121-133. https://doi. org/10.1016/S0016-7169(13)71467-3

Ares, A., Aboal, J.R., Carballeira, A., Giordano, S., Adamo, P., Fernández, J.A., 2012, Moss bag biomonitoring: A methodological review: Science of the Total Environment, 432, 143-158. https://doi.org/10.1016/j. scitotenv.2012.05.087

Ashbaugh, L.L., 1983, A statistical trajectory technique for determining air pollution source regions: Journal of the Air Pollution Control Association, 33, 1096-1098. https:// doi.org/10.1080/00022470.1983.10465702

Baklanov, A., Molina, L.T., Gauss, M., 2016, Megacities, air quality and climate: Atmospheric Environment, 126, 235-249. https://doi.org/10.1016/j. atmosenv.2015.11.059

Banerjee, S.K., King, J., Marvin, J., 1981, A rapid method for magnetic granulometry with applications to environmental studies: Geophysical Research Letters, 8(4), 333-336. https://doi.org/10.1029/ GL008i004p00333

Barceló J., Nicolás G., Sabater B., Sánchez R., 2001, Fisiología vegetal, Madrid, Pirámide, $568 \mathrm{p}$.

Barima, Y.S.S., Angaman, D.M., N'Gouran, K.P., Koffi, N.A., Kardel, F., De Cannière, C., Samson, R., 2014, Assessing atmospheric particulate matter distribution based on Saturation Isothermal Remanent Magnetization of herbaceous and tree leaves in a tropical urban environment: Science of the Total Environment, 470 471, 975-982. https://doi.org/10.1016/j. scitotenv.2013.10.082

Bautista Zúñiga, F., 1999, Introducción al estudio de la contaminación del suelo por metales pesados: Universidad Autónoma de Yucatán, Yucatán, 109 p.

Bautista, F., Cejudo-Ruiz, R., Aguilar-Reyes, B., Gogichaishvili, A., 2014, El potencial del magnetismo en la clasificación de suelos: una revisión: Boletín de la Sociedad Geológica Mexicana, 66(2), 365-376. https://doi. org/10.18268/bsgm2014v66n2al 1

Bautista, F., Campuzano, E., Delgado, C., Goguitchaichvili, A., 2017, Índices de sorción de metales pesados en suelos urbanos: el caso de Morelia Michoacán: Boletín de la Sociedad Geológica Mexicana, 69(2), 433-445. https://doi.org/10.18268/

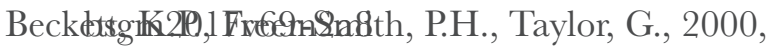
Particulate pollution capture by urban trees: Effect of species and windspeed: Global Change Biology 6, 995-1003. https://doi. org/10.1046/j.1365-2486.2000.00376.x

Blanchard, C.L., 2004, Spatial and Temporal Characterization of Particulate Matter, in McMurry, P., Shepherd, M., and Vickery, J. eds, Particulate Matter Science for Policy Makers: A NARSTO Assessment United Kingdom, Cambridge University Press, 191-234

Borge, R., Lumbreras, J., Vardoulakis, S., Kassomenos, P., Rodríguez, E., 2007, Analysis of long-range transport influences on urban $\mathrm{PM}_{10}$ using two-stage atmospheric trajectory clusters: Atmospheric Environment 41(21), 4434-4450. https://doi.org/10.1016/j. atmosenv.2007.01.053

Bourliva, A., Papadopoulou, L., Aidona, E., Giouri, K., Simeonidis, K., Vourlias, G., 2017, Characterization and geochemistry of technogenic magnetic particles (TMPs) in contaminated industrial soils: Assessing health risk via ingestion: Geoderma, 295, 86-97. https://doi.org/10.1016/j. geoderma.2017.02.001

Boyko, T., Scholger, R., Stanjek, H., 2004, Topsoil magnetic susceptibility mapping as a tool for pollution monitoring: Repeatability of 
in situ measurements: Journal of Applied Geophysics, 55(3-4), 249-259. https://doi. org/10.1016/j.jappgeo.2004.01.002

Brady, N.G., Weil, R.R., 2002, The Nature and Properties of Soils, $13^{\text {th }}$ Edition, Upper Saddle River, New Jersey, Prentice Hall, 960p.

Cao, J., 2017, The Importance of Aerosols in the Earth System: Science and Engineering Perspectives: Aerosol Science and Engineering, 1(1), 1-6. https://doi. org/10.1007/s41810-017-0005-1

Cardoso-Gustavson, P., Fernandes, F.F., Alves, E.S., Victorio, M.P., Moura, B.B., Domingos, M., Rodrigues, G.A., Ribeiro, A.P., Nievola, C.C., Figueiredo, A.M.G., 2016, Tillandsia usneoides: a successful alternative for biomonitoring changes in air quality due to a new highway in São Paulo, Brazil: Environmental Science and Pollution Research, 23, 1779-1788. https:// doi.org/10.1007/s1 1356-015-5449-8

Castanheiro, A., Samson, R., De Wael, K., 2016, Magnetic- and particle-based techniques to investigate metal deposition on urban green: Science of the Total Environment, $571(2016), \quad 594-602$. doi.org/10.1016/j. scitotenv.2016.07.026

Castañeda Miranda, A.G., Chaparro, M.A.E., Chaparro, M.A.E., Böhnel, H.N., 2016, Magnetic properties of Tillandsia recurvata $\mathrm{L}$. and its use for biomonitoring a Mexican metropolitan area: Ecological Indicators, 60, 125-136. doi.org/10.1016/j. ecolind.2015.06.025

Cejudo-Ruíz, R., Bautista, F., Quintana, P., Delgado-Carranza, M.C., Aguilar, D., Goguitchaichvili, A., Morales-Contreras, J.J., 2015, Correlación entre elementos potencialmente tóxicos y propiedades magnéticas en suelos de la Ciudad de México para la identificación de sitios contaminados: definición de umbrales magnéticos: Revista
Mexicana de Ciencias Geológicas, 32(1), 50-61.

Chaparro, M.A.E., Gogorza, C.S.G., Chaparro, M.A.E., Irurzun, M., Sinito, A.M., 2006, Review of magnetism and heavy metal pollution studies of various environments in Argentina: Earth, Planets and Space, 58(10), 1411-1422. https://doi.org/10.1186/ BF03352637

Chaparro, M.A.E., Lavornia, J.M., Chaparro, M.A.E., Sinito, A.M., 2013, Biomonitors of urban air pollution: Magnetic studies and SEM observations of corticolous foliose and microfoliose lichens and their suitability for magnetic monitoring: Environmental Pollution, 172, 61-69. https://doi. org/10.1016/j.envpol.2012.08.006

Cornell, R.M., 1991, Simultaneous Incorporation of $\mathrm{Mn}, \mathrm{Ni}$ and $\mathrm{Co}$ in the Goethite (a-FeOOH) Structure: Clay Minerals, 26(3), 427-430. https://doi.org/10.1180/ claymin.1991.026.3.11

Cornell, R.M., Schwertmann, U., 2003, The iron oxides: structure, properties, reactions, occurrences and uses: Weinheim, WileyVCH GmbH \& Co. KgaA

Cortés, J.L., Bautista, F., Quintana, P., Aguilar, D., Goguichaishvili, A., 2015, The color of urban dust as an indicator of contamination by potentially toxic elements: the case of Ensenada, Baja California, Mexico: Revista Chapingo Serie Ciencias Forestales y del Ambiente, XXI(3), 255-266. https://doi. org/10.5154/r.rchscfa.2015.02.003.

Curtis, L., Rea, W., Smith-Willis, P., Fenyves, E., Pan, Y., 2006, Adverse health effects of outdoor air pollutants: Environment International, 32(6), 815-830. https://doi. org/10.1016/j.envint.2006.03.012

Davidson, C.I., Phalen, R.F., Solomon, P.A., 2005, Airborne Particulate Matter and Human Health: A Review: Aerosol Science and Technology, 39(8), 737-749. https://doi. org/10.1080/02786820500191348 
Day, R., Fuller, M., Schmidt, V.A., 1977, Hysteresis properties of titanomagnetites: Grain-size and compositional dependence: Physics of the Earth and Planetary Interiors, 13(4), 260-267. https://doi. org/10.1016/0031-9201(77)90108-X

Dearing, J.A., Dann, R.J.L., Hay, K., Lees, J.A., Loveland, P.J., Maher, B.A., O’Grady, K., 1996, Frequency-dependent susceptibility measurements of environmental materials: Geophysical Journal International, 228240. https://doi.org/10.1111/j.1365246X.1996.tb06366.x

Dekkers, M., 1997, Environmental magnetism: an introduction: Geology en Mijnbouw, 76, 163-182. https://doi. org/10.1023/A: 1003122305503

Dekkers, M., Schoonen, M.A.A., 1994, An electrokinetic study of synthetic greigite and pyrrhotite: Geochimica et Cosmochimica Acta, 58(19), 4147-4153. https://doi. org/10.1016/0016-7037(94)90270-4

de Kok, T.M.G.M., Driece, H.A.L., Hogervorst, J.G.F., Briedé, J.J., 2006, Toxicological assessment of ambient and traffic-related particulate matter: A review of recent studies: Mutation Research - Reviews in Mutation Research, 613(2-3), 103-122. https://doi. org/10.1016/j.mrrev.2006.07.001

Dominici, F., Peng, R.D., Bell, M.L., Pham, L., Mcdermott, A., Zeger, S.L., Samet, J.M., 2006, Fine Particulate Air Pollution and Hospital Admission for Cardiovascular and Respiratory Diseases: Journal of the American Medical Association, 295(10), 1127-1134. https://doi.org/10.1001/ jama.295.10.1127

Dunlop, D.J., Ö. Özdemir, 1997, Rock Magnetism, Fundamentals and Frontiers: Cambridge, United Kingdom, Cambridge University Press, 596p.

Dunlop, D.J., 2002a, Theory and application of the Day plot $\left(\mathrm{M}_{\mathrm{rs}} / \mathrm{M}_{\mathrm{s}}\right.$ versus $\mathrm{H}_{\mathrm{cr}}$ ' $\left.\mathrm{H}_{c}\right)$ 1. Theoretical curves and tests using titanomagnetite data:Journal of Geophysical
Research, 107(B3), 1-22. https://doi. org/10.1029/2001JB000486

Dunlop, D.J., 2002b, Theory and application of the Day plot $\left(\mathrm{M}_{\mathrm{rs}} / \mathrm{M}_{\mathrm{s}}\right.$ versus $\mathrm{H}_{\mathrm{cr}}$ ' $\left.\mathrm{H}_{\mathrm{c}}\right)$ 2. Application to data for rocks, sediments, and soils: Journal of Geophysical Research, 107(B3), 1-15. https://doi. org/10.1029/2001JB000487

Durža, O., 1999, Heavy metals contamination and magnetic susceptibility in soils around metallurgical plant: Physics and Chemistry of the Earth, Part A: Solid Earth Geodesy, 24, 541-543. https://doi.org/10.1016/ S1464-1895(99)00069-1

Esworthy, R., 2013, Air quality: EPA's 2013 changes to the particulate matter (PM) standard, Congressional Research Service 7-5700, n. R42934, 49p.

Evans, M., Heller, F. (2003). Environmental magnetism: principles and applications of enviromagnetics (Vol. 86). Academic Press, 299p.

Flanders, P.J., 1994, Collection, measurement, and analysis of airborne particulates from pollution in the environment: Journal of Applied Physics, 75(10), 5931-5936. https:// doi.org/10.1063/1.355518

Flanders, P.J., 1999, Identifying fly ash at a distance from fossil fuel power stations: Environmental Science \& Technology, 33(4), 528-532. https://doi.org/10.1021/es980942s

Forster, T., Evans, M.E., Heller, F., 1994, The frequency dependence of low field susceptibility in loess sediments: Geophysical Journal International, 118(3), 636-642. https://doi.org/10.1111/j.1365-246x.1994. tb03990.x

Foth H.D., 1990, Fundamentals of soil science 8th Edition: New York, $8^{\text {th }}$ John Wiley and Sons, 360p.

Frančišković-Bilinski, S., Scholger, R., Bilinski, H., Tibljaš, D., 2014, Magnetic, geochemical and mineralogical properties of sediments from karstic and flysch rivers of Croatia 
and Slovenia: Environmental Earth Sciences, 72(10), 3939-3953. https://doi. org/10.1007/s12665-014-3282-x

Fuzzi, S., Baltensperger, U., Carslaw, K., Decesari, S., Denier Van Der Gon, H., Facchini, M.C., Fowler, D., Koren, I., Langford, B., Lohmann, U., Nemitz, E., Pandis, S., Riipinen, I., Rudich, Y., Schaap, M., Slowik, J.G., Spracklen, D.V., Vignati, E., Wild, M., Williams, M., Gilardoni, S., 2015, Particulate matter, air quality and climate: Lessons learned and future needs: Atmospheric Chemistry and Physics, 15(14), 8217-8299. https://doi.org/10.5194/acp-15-8217-2015

Garçon, G., Shirali, P., Garry, S., Fontaine, M., Zerimech, F., Martin, A., Hannothiaux, M.H., 2000, Polycyclic aromatic hydrocarbon coated onto $\mathrm{Fe}_{2} \mathrm{O}_{3}$ particles: Assessment of cellular membrane damage and antioxidant system disruption in human epithelial lung cells (L132) in culture: Toxicology Letters, 117(1-2), 25-35. https://doi.org/10.1016/ S0378-4274(00)00231-9

Giordano, S., Adamo, P., Spagnuolo, V., Tretiach, M., Bargagli, R., 2013, Accumulation of airborne trace elements in mosses, lichens and synthetic materials exposed at urban monitoring stations: Towards a harmonisation of the moss-bag technique: Chemosphere, 90(2), 292-299. https://doi. org/10.1016/j.chemosphere.2012.07.006

Georgeaud, V.M., Rochette, P., Ambrosi, J.P., Vandamme, D., Williamson, D., 1997, Relationship Between Heavy Metals and Magnetic Properties in a Large Polluted Catchment: The Etang de Berre (South of France): Physics and Chemistry of the Earth, 22(1), 211-214. https://doi.org/10.1016/ S0079-1946(97)00105-5

Gieré, R., Blackford, M., Smith, K., 2006, TEM study of $\mathrm{PM}_{2.5}$ emitted from coal and tire combustion in a thermal power station: Environmental Science and
Technology, 40(20), 6235-6240. https://doi. org/10.1021/es060423m

Goguitchaichvili, A., Morales, J., UrrutiaFucugauchi, J., Soler, A.M., 2001, On the use of continuous thermomagnetic curves in paleomagnetism: A cautionary note: Comptes Rendus de l'Academie de Sciences - Series IIA: Sciences de La Terre et Des Planètes, 333(11), 699-704. https://doi. org/10.1016/S1251-8050(01)01686-X

Goodman, G.T., Roberts, T.M., 1971, Plants and soils as indicators of metals in the air: Nature, 231(5301), 287-292. https://doi. org/10.1038/231287a0

Górka-Kostrubiec, B., Szczepaniak-Wnuk, I., 2017, Magnetic study of a mixture of magnetite and metallic iron in indoor dust samples: Air Quality, Atmosphere and Health, 10(1), 105-116. https://doi. org/10.1007/s1 1869-016-0412-5

Hakanson, L., 1980, An ecological risk index for aquatic pollution control. A sedimentological approach: Water Research, 14(8), 975-1001. https://doi. org/10.1016/0043-1354(80)90143-8

Hanesch, M., Petersen, N., 1999, Magnetic properties of a recent parabrown-earth from Southern Germany: Earth and Planetary Science Letters, 169(1-2), 85-97. https:// doi.org/10.1016/S0012-821X(99)00076-X

Hanesch, M., Scholger, R., 2002, Mapping of heavy metal loadings in soils by means of magnetic susceptibility measurements: Environmental Geology, 42(8), 857-870.

Hanesch, M., Rantitsch, G., Hemetsberger, S., Scholger, R., 2007, Lithological and pedological influences on the magnetic susceptibility of soil: Their consideration in magnetic pollution mapping: Science of the Total Environment, 382(2-3), 351-363. https://doi.org/10.1016/j. scitotenv.2007.04.007. 
Hansard, R., Maher, B.A., Kinnersley, R.P., 2012, Rapid magnetic biomonitoring and differentiation of atmospheric particulate pollutants at the roadside and around two major industrial sites in the U.K: Environmental Science and Technology 46, 4403-4410. https://doi.org/10.1021/ es203275r

Heo, J., Park, J.-S., Kim, B.M., Kim, S.-W., Park, R.J., Jeon, H., Yoon, S.-C., 2017, Two notable features in PM10 data and analysis of their causes: Air Quality, Atmosphere \& Health. https://doi.org/10.1007/ s1 1869-017-0488-6

Hinds, W.G., 1999, Aerosol technology: properties, behavior, and measurement of airborne particles 2nd ed.: New York, Ed. Wiley, 504p.

Hjortenkrans,D., Bergbäck, B., Häggerud, A., 2006, New metal emission patterns in road traffic environments: Environmental Monitoring and Assessment 117, 85-98. https://doi. org/10.1007/s10661-006-7706-2

Hofman,J., Maher, B.A., Muxworthy, A.R., Wuyts, K., Castanheiro, A., Samson, R., 2017, Biomagnetic Monitoring of Atmospheric Pollution: A Review of Magnetic Signatures from Biological Sensors: Environmental Science and Technology, 51(12), 6648-6664. https://doi.org/10.1021/acs.est.7b00832

Hoffmann, V., Knab, M., Appel, E., 1999, Magnetic susceptibility mapping of roadside pollution: Journal of Geochemical Exploration, 66(1-2), 313-326. doi. org/10.1016/S0375-6742(99)00014-X

Holgate, S.T., Koren, H.S., Samet, J.M., Maynard, R.L. (Eds.), 1999, Air pollution and health: Cambridge, Academic Press, 1065p.

Hu, X., Zhang, Y., Ding, Z., Wang, T., Lian, H., Sun, Y., Wu, J., 2012, Bioaccessibility and health risk of arsenic and heavy metals $(\mathrm{Cd}$, $\mathrm{Co}, \mathrm{Cr}, \mathrm{Cu}, \mathrm{Ni}, \mathrm{Pb}, \mathrm{Zn}$ and $\mathrm{Mn}$ ) in TSP and $\mathrm{PM}_{2.5}$ in Nanjing, China: Atmospheric Environment, 57, 146-152. https://doi. org/10.1016/j.atmosenv.2012.04.056
Johansson, C., Norman, M., Gidhagen, L., 2007, Spatial \& temporal variations of PM10 and particle number concentrations in urban air: Environmental Monitoring and Assessment, 127(1-3), 477-487. https://doi. org/10.1007/s10661-006-9296-4

Jones, A.M., Harrison, R.M., Baker, J., 2010, The wind speed dependence of the concentrations of airborne particulate matter and NOx: Atmospheric Environment, 44(13), 1682-1690. https://doi.org/10.1016/j. atmosenv.2010.01.007

Jordanova, D., Petrov, P., Hoffmann, V., Gocht, T., Panaiotu, C., Tsacheva, T., Jordanova, N., 2010, Magnetic Signature of Different Vegetation Species in Polluted Environment: Studia Geophysica et Geodaetica, 54(3), 417-442. https://doi.org/10.1007/ s1 1200-010-0025-7

Jordanova, N., Jordanova, D., Tsacheva, T., 2008, Application of magnetometry for delineation of anthropogenic pollution in areas covered by various soil types. Geoderma, 144(34), 557-571. https://doi.org/10.1016/j. geoderma.2008.01.021

Jordanova, N., Petrovský, E., Kapicka, A., Jordanova, D., Petrov, P., 2017, Application of magnetic methods for assessment of soil restoration in the vicinity of metallurgical copper-processing plant in Bulgaria; Environmental Monitoring and Assessment, 189(4). https://doi.org/10.1007/ s10661-017-5834-5.

Kanu, M.O., Meludu, O.C., Oniku, S.A., 2014, Comparative study of top soil magnetic susceptibility variation based on some human activities: Geofísica Internacional, 53(4), 411-423. https://doi.org/10.1016/ S0016-7169(14)70075-3

Kapička, A., Petrovský, E., Ustjak, S., Macháčková, K., 1999, Proxy mapping of fly-ash pollution of soils around a coal- burning power plant: a case study in the Czech Republic: Journal of Geochemical Exploration, 
66, 291-297. https://doi.org/10.1016/ S0375-6742(99)00008-4

Kardel, F., Wuyts, K., Maher, B.A., Hansard, R., Samson, R., 2011, Leaf saturation isothermal remanent magnetization (SIRM) as a proxy for particulate matter monitoring: Inter-species differences and in-season variation; Atmospheric Environment, 45(29), 5164-5171. https://doi.org/10.1016/j. atmosenv.2011.06.025

Knab, M., Hoffmann, V., Petrovský, E., Kapička, A., Jordanova, N., Appel, E., 2006, Surveying the anthropogenic impact of the Moldau river sediments and nearby soils using magnetic susceptibility: Environmental Geology, 49(4), 527-535. https://doi.org/10.1007/ s00254-005-0080-5

Kim, K.-H., Kabir, E., Kabir, S., 2015, A review on the human health impact of airborne particulate matter: Environment International, 74, 136-143. https://doi. org/10.1016/j.envint.2014.10.005

King, J., Banerjee, S.K., Marvin, J., Özdemir, Ö., 1982, A comparison of different magnetic methods for determining the relative grain size of magnetite in natural materials: some results from lake sediments: Earth and Planetary Science Letters, 59(2), 404-419. https://doi. org/10.1016/0012-821X(82)90142-X

Kopcewicz, B., Kopcewicz, M., 1978, On the determination of sources of iron in atmospheric air by the Mössbauer technique: Tellus, 30(6), 562-568. https://doi. org/10.3402/tellusa.v30i6.10403

Kopcewicz, B., Kopcewicz, M., 2001, Longterm measurements of iron-containing aerosols by Mössbauer spectroscopy in Poland: Atmospheric Environment, 35(21), 3739-3747. https://doi.org/10.1016/ S1352-2310(00)00131-X

Lecoanet, H., Léveque, F., Ambrosi, J.P., 2003, Combination of magnetic parameters: An efficient way to discriminate soilcontamination sources (south France):
Environmental Pollution, 122(2), 229-234. https://doi.org/10.1016/ S0269-7491(02)00299-3

Lehndorff, E., Urbat, M., Schwark, L., 2006, Accumulation histories of magnetic particles on pine needles as function of air quality: Atmospheric Environment, 40(36), 7082-7096. https://doi.org/10.1016/j. atmosenv.2006.06.008

Leonard, R.J., McArthur, C., Hochuli, D.F., 2016, Particulate matter deposition on roadside plants and the importance of leaf trait combinations: Urban Forestry and Urban Greening, 20, 249-253. https://doi. org/10.1016/j.ufug.2016.09.008

Li, Y., Zhang, H., Tu, C., Song, F., Luo, Y., 2017, Occurrence of red clay horizon in soil profiles of the Yellow River Delta: Implications for accumulation of heavy metals: Journal of Geochemical Exploration, 176, 120-127. https://doi.org/10.1016/j. gexplo.2015.11.006

Li, R., Kuo, Y.-M., Liu, W., Jang, C.-S., Zhao, E., Yao, L., 2018, Potential health risk assessment through ingestion and dermal contact arsenic-contaminated groundwater in Jianghan Plain, China: Environmental Geochemistry and Health, (Mcl). https:// doi.org/10.1016/j.gexplo.2015.11.006

Lindbom, J., Gustafsson, M., Blomqvist, G., Dahl, A., Gudmundsson, A., Swietlicki, E., Ljungman, A.G., 2006, Exposure to wear particles generated from studded tires and pavement induces inflammatory cytokine release from human macrophages: Chemical Research in Toxicology, 19, 521-530. https://doi.org/10.1021/tx0503101

Liu, G., Hsu, P.C., Lee, H.W., Ye, M., Zheng, G., Liu, N., Li, W., Cui, Y., 2015, Transparent air filter for high-efficiency $\mathrm{PM}_{2.5}$ capture: Nature Communications, 6, 1-9. https:// doi.org/10.1038/ncomms7205

Liu,D., Wu, X., Du, Y., Sun,L. (2017). Experimental study on the magnetic characteristics of coal fly ash at different combustion temperatures: 
Environmental Technology, 39(15), 19671975. https://doi.org/10.1080/21622515.2 017.1345987

Liu, Q., Roberts, A.P., Larrasoaña, J.C., Banerjee, S.K., Guyodo, Y., Tauxe, L., Oldfield, F., 2012, Environmental Magnetism: Principles and Applications: Reviews of Geophysics, 50, 1-50. https://doi. org/10.1029/2012RG000393

Lu, S.G., Wang, H.Y., Guo, J.L., 2011, Magnetic enhancement of urban roadside soils as a proxy of degree of pollution by traffic-related activities: Environmental Earth Sciences 64, 359-371. https://doi.org/10.1007/ s12665-010-0859-x

Luo, X., Yu, S., Zhu, Y., Li, X. (2012). Trace metal contamination in urban soils of China: Science of The Total Environment, 421-422, 17-30. https://doi.org/10.1016/j. scitotenv.2011.04.020

Magiera, T., Strzyszcz, Z., Kapicka, A., Petrovsky, E., 2006, Discrimination of lithogenic and anthropogenic influences on topsoil magnetic susceptibility in Central Europe: Geoderma, 130(3-4), 299-311. https://doi. org/10.1016/j.geoderma.2005.02.002

Maher, B.A.,1986,. Characterisation of soils by mineral magnetic measurements: Physics of the Earth and Planetary Interiors, 42(1-2), 76-92. https://doi.org/10.1016/ S0031-9201(86)80010-3

Maher, B.A., 1988, Magnetic properties of some synthetic sub-micron magnetites: Geophysical Journal, 94(1), 83-96. https:// doi.org/10.1111/j.1365-246X.1988. tb03429.x

Maher, B.A., Thompson, R. (Eds.), 1999, Quaternary climates, environments and magnetism: Cambridge, NY, Cambridge University Press, 390p.

Maher, B.A., 2007, Environmental Magnetism, in Gubbins, D., Herrero-Bervera, E. (eds.), Encyclopedia of geomagnetism and paleomagnetism: Dordrecht, Springer Science \& Business Media, 248-256.

Maher, B.A., Moore, C., Matzka, J., 2008, Spatial variation in vehicle-derived metal pollution identified by magnetic and elemental analysis of roadside tree leaves: Atmospheric Environment, 42(2), 364-373. https://doi. org/10.1016/j.atmosenv.2007.09.013

Maher, B.A., Ahmed, I.A.M., Karloukovski, V., MacLaren, D.A., Foulds, P.G., Allsop, D., Mann, D.M.A.,Torres-Jardón, R., Calderon-Garciduenas, L., 2016, Magnetite pollution nanoparticles in the human brain: Proceedings of the National Academy of Sciences of the United States of America, 113:10797-10801. https://doi. org/10.1016/j.envpol.2011.08.017

Malm, W.C., 2003, Fundamentals of visibility in Potter, T.D., Colman, B.R., (eds.), Handbook of Weather, Climate and Water: Atmospheric Chemistry, Hydrology, and Societal Impacts: Hoboken, New Jersey, Wiley-Interscience,285-329.

Matzka, J., Maher, B.A., 1999, Magnetic biomonitoring of roadside tree leaves: Identification of spatial and temporal variations in vehicle-derived particulates: Atmospheric Environment, 33(28), 4565-4569. https://doi.org/10.1016/ S1352-2310(99)00229-0

Michaelides, S., Paronis, D., Retalis, A., Tymvios, F., 2017, Monitoring and Forecasting Air Pollution Levels by Exploiting Satellite, Ground-Based, and Synoptic Data, Elaborated with Regression Models: Advances in Meteorology, 2017, 17. https:// doi.org/10.1155/2017/2954010

Mitchell, R., Maher, B.A., Kinnersley, R., 2010, Rates of particulate pollution deposition onto leaf surfaces: Temporal and interspecies magnetic analyses: Environmental 
Pollution, 158(5), 1472-1478. https://doi. org/10.1016/j.envpol.2009.12.029

Mokdad, A.H., Marks, J.S., Stroup, D.F., Gerberding, J.L., 2004, Actual Causes of Death in the United States, 2000: Journal of the American Medical Association, 291(10), 1238-1246. https://doi.org/10.1001/ jama.1993.03510180077038

Morales J., Hernández-Bernal M. del S., Corona-Chávez P., Gogichaishvili, A., Bautista, F., 2016, Further evidence for magnetic susceptibility as a proxy for the evaluation of heavy metals in mining wastes: case study of Tlalpujahua and El Oro Mining Districts: Environmental Earth Sciences 75:309. https://doi.org/10.1007/ s12665-015-5187-8

Moreno, E., Sagnotti, L., Dinarès-Turell, J., Winkler, A., Cascella, A., 2003, Biomonitoring of traffic air pollution in Rome using magnetic properties of tree leaves: Atmospheric Environment, 37(21), 2967-2977. https://doi.org/10.1016/ S1352-2310(03)00244-9

Morris, W.A., Versteeg, J.K., Bryant, D.W., Legzdins, A.E., McCarry, B.E., Marvin, C.H., 1995, Preliminary comparisons between mutagenicity and magnetic susceptibility of respirable airborne particulate: Atmospheric Environment, 29(23), 3441-3450. https:// doi.org/10.1016/1352-2310(95)00203-B

Müller G., 1969, Index of geoaccumulation in sediments of the Rhine River. Geojournal 2:108-18.

Müller, G., 1986, Schadstoffe in SedimentenSedimente als Schadstoffe. Mitt, österr. Geol. Ges., 79, 107-126.

Munsell Color, 2000, Munsell soil color charts. Revised washable edition: MI, USA: GretagMacbeth.

Muxworthy, A.R., Schmidbauer, E., Petersen, N., 2002, Magnetic properties and Mössbauer spectra of urban atmospheric particulate matter: a case study from Munich, Germany: Geophysical Journal International,
10(January), 558-570. https://doi. org/10.1046/j.1365-246X.2002.01725.x

Oberdörster, G., 2001, Pulmonary effects of inhaled ultrafine particles: International Archives of Occupational and Environmental Health, 74(1), 1-8. https://doi.org/10.1007/ s004200000185

Oldfield, F., Brown, A., Thompson, R., 1979, The effect of microtopography and vegetation on the catchment of airborne particles measured by remanent magnetism: Quaternary Research, 12(3), 326-332. https://doi. org/10.1016/0033-5894(79)90032-2

Oldfield, F., Scoullos, M., 1984, Particulate pollution monitoring in the Elefsis Gulf: The role of mineral magnetic studies. Marine Pollution Bulletin, 15(6), 229-231. https:// doi.org/10.1016/0025-326X(84)90294-7

Pandey P., Kumar D., Prakash A., Masih J., Singh M., Kumar S., Kumar Jain V., Kumar K., 2012, A study of urban heat island and its association with particulate matter during winter months over Delhi. Science of the Total Environment 414: 494-507. https:// doi.org/10.1016/j.scitotenv.2011.10.043

Perez, P., Reyes, J., 2006, An integrated neural network model for $\mathrm{PM}_{10}$ forecasting: Atmospheric Environment, 40(16), 2845-2851. https://doi.org/10.1016/j. atmosenv.2006.01.010

Perrino, G., 2010, Atmospheric particulate matter in Proceedings of a C.I.S.B. Minisymposium, Rome, Italy 35-43.

Peters, C., Dekkers, M.J., 2003, Selected room temperature magnetic parameters as a function of mineralogy, concentration and grain size, Physics and Chemistry of the Earth, 28, 659-667. https://doi. org/10.1016/S1474-7065(03)00120-7

Petrovský, E., Ellwood, B.B., 1999, Magnetic monitoring of air-, land- and water pollution, in Maher, B. A., Quaternary climates, 
environments and magnetism: Cambridge, Cambridge University Press, 279-322.

Petrovský, E., Kapička, A., Jordanova, N., Borůvka, L., 2001, Magnetic properties of alluvial soils contaminated with lead, zinc and cadmium: Journal of Applied Geophysics, 48:127-136. https://doi.org/10.1016/ s0926-9851(01)00085-4

Pike, G.R., Roberts, A.P., Verosub, K.L., 1999, Characterizing interactions in fine magnetic particle systems using first order reversal curves: Journal of Applied Physics, 85(9), 6660. https://doi.org/10.1063/1.370176

Pope III, C.A., Schwartz, J., Ransom, M.R., 1992, Daily Mortality and PM10 in Utah Valley: Archives of Environmental Health, 47(3), 211-217. https://doi.org/10.1080/0003989 6.1992 .9938351 .

Pui, D.Y.H., Cao, J., An, Z., Wang, J., 2014, Great wall of solar panels to mitigate yellow dust storm. Particuology, 13(1), 146-150. https:// doi.org/10.1016/j.partic.2014.03.002

Qu, C.S., Ma, Z.W., Yang, J., Liu, Y., Bi, J., Huang, L., 2012, Human Exposure Pathways of Heavy Metals in a Lead-Zinc Mining Area, Jiangsu Province, China: PLoS ONE, 7(11). https://doi.org/10.1371/journal. pone.0046793.

Qiao Q., Huang B., Piper J.D.A., Biggin, A.J., Zhang, C., 2017, The characteristics of environmental particulate matter in the urban area of Beijing, China, during the 2008 Olympic Games: Atmospheric Pollution Research 8:141-148. https://doi. org/10.1016/j.apr.2016.08.003

Rachwal, M., Kardel, K., Magiera, T., Bens, O., 2017, Application of magnetic susceptibility in assessment of heavy metal contamination of Saxonian soil (Germany) caused by industrial dust deposition: Geoderma, 295, 10-21. https://doi.org/10.1016/j. geoderma.2017.02.007

Radhakrishnamurty, G., Likhite, S.D., Sastry, N.P., 1971, Low temperature magnetic hysteresis of fine particle aggregates occuring in some natural samples. The Philosophical Magazine:
A Journal of Theoretical Experimental and Applied Physics, 23(182), 503-507. https:// doi.org/10.1080/14786437108216400.

Revuelta, M.A., McIntosh, G., Pey, J., Pérez, N., Querol, X., Alastuey, A., 2014, Partitioning of magnetic particles in $\mathrm{PM}_{10}, \mathrm{PM}_{2.5}$ and $\mathrm{PM}_{1}$ aerosols in the urban atmosphere of Barcelona (Spain): Environmental Pollution, 188, 109-117. https://doi.org/10.1016/j. envpol.2014.01.025

Rai, P.K., 2013, Environmental magnetic studies of particulates with special reference to biomagnetic monitoring using roadside plant leaves. Atmospheric Environment, 72, 113-129. https://doi.org/10.1016/j. atmosenv.2013.02.041

Rai, P.K., 2016,. Biomagnetic monitoring of particulate matter (PM) through an invasive alien plant Lantana camara in Biomagnetic Monitoring of Particulate Matter in the Indo-Burma Hotspot Region. https://doi. org/10.1016/B978-0-12-805135-1.00010-X

Robinson, S.G., 1986, The late Pleistocene palaeoclimatic record of North Atlantic deepsea sediments revealed by mineral-magnetic measurements: Physics of the Earth and Planetary Interiors, 42(1-2), 22-47. https:// doi.org/10.1016/S0031-9201(86)80006-1

Rodríguez-Germade, I., Mohamed, K.J., Rey, D., Rubio, B., García, Á., 2014, The influence of weather and climate on the reliability of magnetic properties of tree leaves as proxies for air pollution monitoring: Science of the Total Environment, 468469, 892-902. https://doi.org/10.1016/j. scitotenv.2013.09.009

Rohr, A.C., Wyzga, R.E., 2012, Attributing health effects to individual particulate matter constituents: Atmospheric Environment, 62, 130-152. https://doi.org/10.1016/j. atmosenv.2012.07.036

Rose, A.W., Bianchi-Mosquera, G.C., 1993, Adsorption of $\mathrm{Cu}, \mathrm{Pb}, \mathrm{Zn}, \mathrm{Co}, \mathrm{Ni}$, and $\mathrm{Ag}$ on goethite and hematite: a control on metal mobilization from red beds into stratiform 
copper deposits: Economic Geology, 88, 1226-1236. https://doi.org/10.2113/ gsecongeo.88.5.1226

Sadeghian, M.M., 2012, Biomonitoring of particulate matter by magnetic properties of Ulmus carpinifolia leaves: African Journal of Biotechnology, 11(73), 13827-13830. https://doi.org/10.5897/AJB12.564

Sagnotti, L., Macrì, P., Egli, R., Mondinio, M., 2006, Magnetic properties of atmospheric particulate matter from automatic air sampler stations in Latium (Italy): Toward a definition of magnetic fingerprints for natural and anthropogenic PM10 sources: Journal of Geophysical Research: Solid Earth, 111(12), 1-17. https://doi. org/10.1029/2006JB004508

Sagnotti, L., Taddeucci, J., Winkler, A., Cavallo, A., 2009, Compositional, morphological, and hysteresis characterization of magnetic airborne particulate matter in Rome, Italy: Geochemistry, Geophysics, Geosystems 10, 1-17. https://doi. org/10.1029/2009GC002563

Salmani-Ghabeshi, S., Palomo-Marín, M.R., Bernalte, E., Rueda-Holgado, F., MiróRodríguez, C., Cereceda-Balic, F., Fadic, X., Vidal, V., Funes, M., Pinilla-Gil, E., 2016, Spatial gradient of human health risk from exposure to trace elements and radioactive pollutants in soils at the Puchuncaví-Ventanas industrial complex, Chile: Environmental Pollution 218, 322-330. https://doi. org/10.1016/j.envpol.2016.07.007

Sánchez-Duque, A., Bautista, F., Goguitchaichvili, A., Cejudo-Ruiz, R., Reyes-López, J.A., Solís-Domínguez, F.A., Morales-Contreras, J.J., 2015, Evaluación de la contaminación ambiental a partir del aumento magnético en polvos urbanos - Caso de estudio para la ciudad de Mexicali, México: Revista Mexicana de Ciencias Geológicas, 32(3), 501-513.

Sant'Ovaia, H., Lacerda, M.J., Gomes, G., 2012, Particle pollution - An environmental magnetism study using biocollectors located in northern Portugal: Atmospheric Environment, 61, 340-349. https://doi. org/10.1016/j.atmosenv.2012.07.059

Schleicher, N., Norra, S., Chai, F., Chen, Y., Wang, S., Stüben, D., 2010, Anthropogenic versus geogenic contribution to total suspended atmospheric particulate matter and its variations during a two-year sampling period in Beijing, China: Journal of Environmental Monitoring, 12(2), 434-441. https://doi. org/10.1039/B914739J

Scholger, R., 1998, Heavy metal pollution monitoring by magnetic susceptibility measurements applied to sediments of the river Mur (Styria, Austria): European Journal of Environmental and Engineering Geophysics. 3. 25-37.

Scoullos, M., Oldfield, F., Thompson, R., 1979, Magnetic monitoring of marine particulate pollution in the Elefsis Gulf, Greece: Marine Pollution Bulletin, 10(10), 287-291. https:// doi.org/10.1016/0025-326X(79)90198-X

Secretaria de Medio Ambiente y Recursos Naturales (SEMARNAT), 2007, Norma Oficial Mexicana NOM- 147-SEMARNAT/ SSA1-2004, Que establece criterios para determinar las concentraciones de remediación de suelos contaminados por arsénico, bario, berilio, cadmio, cromo hexavalente, mercurio, níquel, plata, plomo, selenio, talio y/o vanadio. Secretaría de Medio Ambiente y Recursos Naturales. Diario Oficial de la Federación. 2 de Marzo 2007, 69 p.

Shah, A.S.V, Lee, K.K., McAllister, D.A., Hunter, A., Nair, H., Whiteley, W., Langrish, J.P., Newby, D.E., Mills, N.L., 2015, Short term exposure to air pollution and stroke: systematic review and meta-analysis. BMJ 350, h1295. https://doi.org/10.1136/bmj. h1295

Sharma, B., Singh, S., Siddiqi, N.J., 2014, Biomedical implications of heavy metals 
induced imbalances in redox systems: BioMed Research International, 2014. https://doi.org/10.1155/2014/640754

Shilton, V.F., Booth, G.A., Smith, J.P., Giess, P., Mitchell, D.J., Williams, C.D., 2005, Magnetic properties of urban street dust and their relationship with organic matter content in the West Midlands, UK: Atmospheric Environment, 39(20), 3651-3659. https:// doi.org/10.1016/j.atmosenv.2005.03.005

Shu, J., Dearing, J.A., Morse, A.P., Yu, L., Yuan, N., 2001, Determining the sources of atmospheric particles in Shanghai, China, from magnetic and geochemical properties: Atmospheric Environment, 35(15), 2615-2625. https://doi.org/10.1016/ S1352-2310(00)00454-4

Silverman, R. A., Ito, K., Freese, J., Kaufman, B. J., De Claro, D., Braun, J., Prezant, D. J., 2010, Association of ambient fine particles with out-of-hospital cardiac arrests in New York city: American Journal of Epidemiology, 172(8), 917-923. https://doi.org/10.1093/ aje/kwq217

Sioutas, C., Delfino, R.J., Singh, M., 2005, Exposure assessment for atmospheric Ultrafine Particles (UFPs) and implications in epidemiologic research: Environmental Health Perspectives 113, 947-955. https:// doi.org/10.1289/ehp.7939

Sirois, A., Bottenheim, J.W., 1995, Use of backward trajectories to interpret the 5-year record of PAN and $\mathrm{O}_{3}$ ambient air concentrations at Kejimkujik National Park, Nova Scotia: Journal of Geophysical Research, 100(D2), 2867-2881. https://doi. org/10.1029/94JD02951

Smith, W.H., 1990, Air Pollution and Forests Interaction Between Air Contaminants and Forest Ecosystems, Second Edition: New York, Springer-Verlag, 518p. https://doi. org/10.1007/978-1-4612-3296-4

Snowball, I., Torii, M., 1999, Incidence and significance of magnetic iron sulphides in Quaternary sediments and soil in Maher, B.A., Thompson, R. (eds.), Quaternary
Climates, Environments and Magnetism: Cambridge, Cambridge University Press, 199-230.

Song, Y., Wang, X., Maher, B.A., Li, F., Xu, C., Liu, X., Sun, X., Zhang, Z., 2016, The spatial-temporal characteristics and health impacts of ambient fine particulate matter in China: Journal of Cleaner Production 112, 1312-1318. https://doi.org/10.1016/j. jclepro.2015.05.006

Spassov, S., Egli, R., Heller, F., Nourgaliev, D.K., Hannam, J., 2004, Magnetic quantification of urban pollution sources in atmospheric particulate matter: Geophysical Journal International, 159(2), 555-564. https://doi. org/10.1111/j.1365-246X.2004.02438.x

Stadlober, E., Huebnerova, Z., Michalek, J., Kolar, M., 2012, Forecasting of Daily $\mathrm{PM}_{10}$ Concentrations in Brno and Graz by Different Regression Approaches: Austrian Journal of Statistics, 41(4), 287-310. https:// doi.org/10.17713/ajs.v4li4.169

Sugiura, N., 1979, ARM, TRM and magnetic interactions: Concentration dependence: Earth and Planetary Science Letters, 42(3), 451-455. https://doi. org/10.1016/0012-821x(79)90054-2

Szönyi, M., Sagnotti, L., Hirt, A.M., 2008, A refined biomonitoring study of airborne particulate matter pollution in Rome, with magnetic measurements on Quercus Ilex tree leaves: Geophysical Journal International, 173(1), 127-141. https://doi. org/10.1111/j.1365-246X.2008.03715.x

Szuszkiewicz, M., Magiera, T., Kapička, A., Petrovský, E., Grison, H., Gołuchowska, B., 2015, Magnetic characteristics of industrial dust from different sources of emission: A case study of Poland: Journal of Applied Geophysics, 116, 84-92. https://doi. org/10.1016/j.jappgeo.2015.02.027

Thompson, R., Stober, J.C., Turner, G.M., Oldfield, F., Bloemendal, J., Dearing, J.A., Rummery, T.A., 1980, Environmental 
applications of magnetic measurements: Science 207, 481-6. https://doi. org/10.1126/science.207.4430.481

Thompson, R., Oldfield, F., 1986, Environmental magnetism. London: Allen and Unwin, 227p. http://dx.doi. org/10.1007/978-94-011-8036-8

Tomlinson, D.L., Wilson, J.G., Harris, C.R., Jeffrey, D.W., 1980, Problems in the assessment of heavy-metal levels in estuaries and the formation of a pollution index: Helgoländer Meeresuntersuchungen, 33(1-4), 566-575. https://doi.org/10.1007/BF02414780

Urbat, M., Lehndorff, E., Schwark, L., 2004, Biomonitoring of air quality in the Cologne Conurbation using pine needles as a passive sampler - Part I: magnetic properties: Atmospheric Environment, 38, 3781-3791. https://doi.org/10.1016/j. atmosenv.2010.04.052.

U.S.EPA., 1996, Soil Screening Guidance: Technical Background Document. EPA/540/R-95/128. Washington DG: U.S. Environmental Protection Agency.

Vassilev, S.V., Vassileva, G.G., 1996, Mineralogy of combustion wastes from coalfired power stations: Fuel Processing Technology, 47(3), 261-280. https://doi. org/10.1016/0378-3820(96)01016-8

Vezzola, L. C., Muttoni, G., Merlini, M., Rotiroti, N., Pagliardini, L., Hirt, A.M., Pelfini, M., 2017, Investigating distribution patterns of airborne magnetic grains trapped in tree barks in Milan, Italy: Insights for pollution mitigation strategies: Geophysical Journal International, 210(2), 989-1000. https://doi. org/10.1093/gji/ggx232

Wadge, A., Hutton, M., Peterson, P.J., 1986, The concentrations and particle size relationships of selected trace elements in fly ashes from U.K. coal-fired power plants and a refuse incinerator: Science of the Total Environment, The, 54(C), 13-27. https:// doi.org/10.1016/0048-9697(86)90253-6

Wang, X., Lvlie, R., Zhao, X., Yang, Z., Jiang, F., Wang, S., 2010, Quantifying ultrafine pedogenic magnetic particles in Chinese loess by monitoring viscous decay of superparamagnetism: Geochemistry, Geophysics, Geosystems, 1 1(10). https://doi. org/10.1029/2010GC003194

Wang, G., Oldfield, F., Xia, D., Chen, F., Liu, X., Zhang, W., 2012, Magnetic properties and correlation with heavy metals in urban street dust: A case study from the city of Lanzhou, China: Atmospheric Environment, 46, 289-298. https://doi.org/10.1016/j. atmosenv.2011.09.059

Wei, B., Yang, L., 2010, A review of heavy metal contaminations in urban soils, urban road dusts and agricultural soils from China. Microchemical Journal, 94(2), 99-107. https://doi.org/10.1016/j. microc.2009.09.014

World Health Organization (WHO), 2000, Air quality guidelines for Europe, Second Edition. WHO Regional Publications, European Series, No. 91, Copenhagen, Denmark.

World Health Organization (WHO), 2006, Air quality guidelines for particulate matter, ozone, nitrogen dioxide and sulfur dioxide: Global update 2005-Summary of risk assessment. Copenhagen, World Health Organization, $20 \mathrm{p}$.

World Health Organization (WHO), 2013, Health effects of particulate matter. Policy implications for countries in Eastern Europe. Caucasus and central Asia. World Health Organization Regional Office for Europe, Copenhagen, World Health Organization, $14 \mathrm{p}$.

World Health Organization (WHO), 2016, Ambient air pollution: a global assessment of exposure and burden of disease. In Ambient air pollution: a global assessment of exposure and burden of disease: Geneva, World Health Organization, $131 \mathrm{p}$.

Wu, Z., Liu, F., Fan, W., 2015, Characteristics of PM10 and PM $_{2.5}$ at Mount Wutai Buddhism Scenic Spot, Shanxi, China: Atmosphere, 1195-1210. https://doi.org/10.3390/ atmos6081195

Wuana, R.A., Okieimen, F.E., 2011 , Heavy Metals in Contaminated Soils: A Review of Sources, Chemistry, Risks and Best Available Strategies 
for Remediation: ISRN Ecology, 2011, 1-20. https://doi.org/10.5402/2011/402647

Xie, S., Dearing, J.A., Bloemendal, J., 2000, The organic matter content of street dust in Liverpool, UK, and its association with dust magnetic properties: Atmospheric Environment, 34(2), 269-275. https://doi. org/10.1016/S1352-2310(99)00209-5

Xing, Y.F., Xu, Y.H., Shi, M.H., Lian, Y.X., 2016, The impact of $\mathrm{PM}_{2.5}$ on the human respiratory system: Journal of Thoracic Disease, 8(1), E69-E74. https://doi. org/10.3978/j.issn.2072-1439.2016.01.19

Xu, X., Zhang, Z., Bao, L., Mo, L., Yu, X., Fan, D., Lun, X., 2017, Influence of rainfall duration and intensity on particulate matter removal from plant leaves: Science of the Total Environment, 609, 11-16. https:// doi.org/10.1016/j.scitotenv.2017.07.141

Yang, T., Liu, Q., Chan, L., Liu, Z., 2007, Magnetic signature of heavy metals pollution of sediments: Case study from the East Lake in Wuhan, China: Environmental Geology, 52(8), 1639-1650. https://doi.org/10.1007/ s00254-006-0609-2.

Yang, P.G., Yang, M., Mao, R.Z., Byrne, J.M., 2015, Impact of long-term irrigation with treated sewage on soil magnetic susceptibility and organic matter content in North China: Bulletin of Environmental Contamination and Toxicology, 95(1), 102-107. https://doi. org/10.1007/s00128-015-1562-0

Zannetti, P., 1990, Air Pollution Modeling Theories, Computational Methods and Available Software. New York: Springer Science \& Business Media, 444 p.

Zhang, C., Huang, B., Li, Z., Liu, H., 2006, Magnetic properties of high-road-side pine tree leaves in Beijing and their environmental significance: Chinese Science Bulletin, 51(24), 3041-3052. https://doi.org/10.1007/ s1 1434-006-2189-7
Zhang, C., Huang, B., Piper, J.D.A., Luo, R., 2008, Biomonitoring of atmospheric particulate matter using magnetic properties of Salix matsudana tree ring cores: Science of the Total Environment, 393(1), 177-190. https:// doi.org/10.1016/j.scitotenv.2007.12.032

Zhang, C., Qiao, Q., Piper, J.D.A., Huang, B., 2011, Assessment of heavy metal pollution from a Fe-smelting plant in urban river sediments using environmental magnetic and geochemical methods: Environmental Pollution, 159(10), 3057-3070. https://doi. org/10.1016/j.envpol.2011.04.006

Zhang, C., Qiao, Q., Appel, E., Huang, B., 2012, Discriminating sources of anthropogenic heavy metals in urban street dusts using magnetic and chemical methods: Journal of Geochemical Exploration, 119-120, 60-75. https://doi.org/10.1016/j. gexplo.2012.06.014

Zhao, G., Lian, M., Yiyun, L., Duan, Z., Zhu, S., Mei, L., Svanberg, S., 2017, Mobile lidar system for environmental monitoring: Applied Optics, 56(5), 1506-1516. https:// doi.org/10.1364/AO.56.001506

Zheng, N., Liu, J., Wang, Q., Liang, Z., 2010, Health risk assessment of heavy metal exposure to street dust in the zinc smelting district, Northeast of China: Science of The Total Environment, 408(4), 726-733.https:// doi.org/10.1016/j.scitotenv.2009.10.075

Zheng, Y., Zhang, S., 2008, Magnetic properties of street dust and topsoil in Beijing and its environmental implications: Chinese Science Bulletin, 53(3), 408-417. https://doi. org/10.1007/s1 1434-007-0450-3

Zhou, H.Y., Wang, X.S., Shan, A.Q. (2015). Discriminating soil-contamination sources using combination of magnetic parameters: Environmental Earth Sciences, 74(7), 5805-5811. https://doi.org/10.1007/ s12665-0 15-4598-x

Zutshi, B., Prasad, S.G.R. (2008). Impact of pollution on fresh- and marine water resources - A review: Pollution Research 27(3), 461-466. https://doi.org/10.1016/j. marpolbul.2003.12.004 